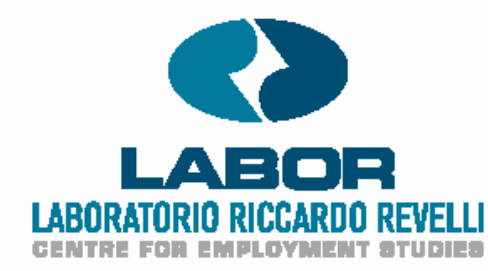

Working Paper no. 23

\title{
Employment Protection Legislation and the Size of Firms
}

\author{
Pietro Garibaldi \\ Università Bocconi, CEPR and FRDB
}

Lia Pacelli

Università di Torino and LABORatorio R. Revelli

Andrea Borgarello

LABORatorio R. Revelli 


\title{
Employment Protection Legislation and the Size of Firms
}

\author{
Pietro Garibaldi ${ }^{\star}$ Lia Pacelli* and Andrea Borgarello*
}

\begin{abstract}
:
The existing literature ignores the fact that in most European countries the strictness of Employment Protection Legislation (EPL) varies across the firm size distribution. In Italy firms are obliged to rehire an unfairly dismissed worker only if they employ more than 15 employees. Theoretically, the paper solves a baseline model of EPL with threshold effects, and shows that firms close to the threshold are characterized by an increase in inaction and by a reluctance to grow. Empirically, the paper estimates transition probability matrices on firm level employment using a longitudinal data set based on Italian Social Security (INPS) records, and finds two results. First, firms close to the 15 employees threshold experience an increase in persistence of 1.5 percent with respect to a baseline statistical model. Second, firms with 15 employees are more likely to move backward than upward. Finally, the paper tests the effect of a 1990 reform which tightened the regulation on individual dismissal only for small firms. It finds that the persistence of small firms relative to large firms increased significantly. Overall, these threshold effects are significant and robust, but quantitatively small.
\end{abstract}

JEL Classification: J4

Key Words: Employment Protection Legislation, Firm Size.

\footnotetext{
${ }^{(\star)}$ Università Bocconi, CEPR and fRDB; ${ }^{(*)}$ Università di Torino and LABORatorio R.Revelli, ${ }^{(\star)}$ LABORatorio R.Revelli. We thank Riccardo Faini, Paolo Sestito, Bruno Contini, Giuseppe Bertola, Tito Boeri, Marco Leonardi, and seminar participants at the Italian Treasury Minister, LABORatorio R.Revelli, Bocconi University, Tilburg, CEPR Workshop on Dynamic Approach to European Unemployment in Berlin for various comments and suggestions. A special thank to Tullio Jappelli (editor) and to an anonymous referee. Address for correspondence: Pietro Garibaldi, Bocconi University, Istituto Economia Politica, Via Sarfatti 25, 20136 Milano Tel: 02-58365422 (fax 3309) email: pietro.garibaldi@uni-bocconi.it
} 


\section{Introduction}

Over the last decade, Employment Protection Legislation (EPL) has attracted a large interest among labour economists and policy makers. The accumulated empirical evidence and theoretical analysis has greatly improved the overall understanding of the effects of EPL on the aggregate labour markets. The main empirical regularities are as follows. EPL reduces unemployment inflows and outflows, but it has ambiguous effects on aggregate employment stocks. In addition, EPL has important effects on the composition of employment, since countries with stricter EPL are associated with higher youth unemployment and larger self employment. These empirical regularities, recently surveyed by the OECD (1999), are broadly in line with the existing theoretical models, who treat EPL as a tax on labour shedding (Bentolila - Bertola, 1990, and Bertola, 1999).

Most of the traditional empirical literature works with macroeconomic data, and analyses the effects of EPL on aggregate labour markets flows and stocks. More recently, different scholars have used individual and firm level data for analysing the effects of various EPL reforms. Acemoglu Angrist (2001) have studied the effects of the Employment Disability Act, while Kugler (1999) has studied the effect of the EPL reform in Colombia. Further, Blanchard - Portugal (2001) have compared the labour market dynamics of U.S. and Portugal, and have found that despite their similar unemployment level, Portugal experiences much lower worker flows in and out of unemployment.

Despite the growing number of studies on EPL based on individual and firm level data, little or no attention has been devoted to the effect of EPL on the size distribution of firms, and on the behaviour of firms of different size. This is surprising, since in most European countries the existing legislation varies across firms of different size. The case of Italy stands out in this respect. In the existing legislation firms with more than 15 employees are obliged to rehire the dismissed employee when a judge rules the dismissal unfair. Small firms, by contrast, are only obliged to compensate the dismissed worker with a monetary transfer. In the Italian context, the 15 employees threshold is certainly relevant, since it leaves below about $30 \%$ of the employees and more than $80 \%$ of private firms. Indeed, small firms are quantitatively more important in Italy relatively to other OECD economies, as was recently shown by Bartelsman et al. (2001).

This paper studies theoretically and empirically the effects of such EPL thresholds on employment dynamics. Theoretically, the paper solves a baseline model of EPL with threshold effects, and shows that firms close to the threshold are characterized by an increase in inaction and by a reluctance to grow. This implies that average employment is affected by size contingent EPL under conditions that would make it independent of uniform EPL provisions. This result is new, and it is due to the flexibility induced by size contingent EPL. Specifically, profit maximizing firms below the threshold face a trade-off between dynamic efficiency (the possibility of adjusting their size in response to future shocks) and average long-run size (the possibility of growing beyond the threshold). Our model shows that there exists a well defined mass of firms that solve such trade-off in favour of dynamic efficiency, and optimally choose not to cross the threshold. Such trade-off does not arise in a world with uniform EPL provision, when firms are forced to solve the same trade-off in terms of a larger average long-run size. As a result, average employment is larger under uniform EPL than under size contingent EPL, even though profits and allocative efficiency are larger in the latter scenario. 
Empirically, the paper uses firm level data drawn from the Italian Social Security (INPS) Archives, and studies whether the existence of the 15 employees threshold modifies employment dynamics, and whether firms' inaction vis-à-vis employment increases close to the 15 employees threshold, as our theoretical model predicts. The paper finds a significant, albeit quantitatively small, threshold effect. Specifically, the paper estimates transition probability matrices for a sample of some 30,000 Italian firms between 1987 and 1996. While the probability of inaction decreases markedly with firm size, it experiences a significant spike in the region below the threshold. Indeed, the paper finds that firms employing 14 and 15 employees have a probability of inaction that is 1.5 percent higher than what different non linear statistical models would predict. Similarly, the difference between the probability of moving down and moving up by one position falls slightly with firm size, but it features a 1.6 percent spike around the 15 employees threshold. Finally, the paper estimates the effect of a 1990 reform which tightened EPL on small firms. Although this is not a natural experiment, because also the legislation referred to the control group changed, the paper finds that the persistence of small firms relatively to large firms increased significantly after 1990.

The paper proceeds as follows. Section 2 looks at the existing legislation, and describes the labour market institutions that apply only to firms of certain size, with particular emphasis on the EPL differential. Section 3 presents a toy model of EPL with threshold effects, and derives two empirical predictions. Section 4 describes the dataset used in the empirical analysis, and presents the methodological approach pursued in the paper. Section 5 presents the results in terms of firm level persistence and firm level probability of increasing and decreasing by one position. Section 6 looks at the 1990 EPL reform which increased firing costs for small firms relatively to large firms. Section 7 summarizes and concludes.

\section{Employment Protection Legislation and Firm Size: The Italian Institutional Setting.}

Within the Italian Institutional settings, there are five types of regulations that depend on firm's size ${ }^{1}$. The institutional areas involved are the following: employment protection legislation, mandatory quotas on hiring, firm level rights to organize union related institutions, firms safety standards and collective dismissals rules. The existence of rules and constraints to be applied only to larger firms can potentially affect firms' size, can push firms to enter in markets in which the optimal long-run position is below the thresholds, and can affect the geographical location of firms and establishments.

The most important institutional constraint is linked to the individual dismissal procedures, as legislated in the Article 18 of the labour code. Within the Italian institutional setting, individual dismissals must be justified by a just cause rule, and workers have the right to appeal firm initiated dismissals $^{2}$. Whenever a judge rules the dismissal unfair, workers are entitled to a compensation that

\footnotetext{
${ }^{1}$ See also Baffi - Baffi (1999).

${ }^{2}$ Here we refer to objective just cause (economic reasons). Subjective just causes (as misconduct) are linked to worker behaviour, and are not the object of our theoretical analysis. In practice, however, it is only a judge ruling that defines a specific situation as subjective or objective.
} 
depends crucially on firm size. Firms employing less than 15 employees must compensate the unlawfully dismissed workers and pay a severance payment that varies between a minimum of 2.5 and a maximum of 6 months (tutela obbligatoria). Conversely, firms employing more than 15 workers must compensate the worker for the foregone wages from the date of the dismissal, and are also obliged to rehire the worker (Article 18, tutela reale) ${ }^{3}$ If the worker does not exercise the option to be reinstated, he or she can receive a severance payment of 15 months. Even though the large majority of dismissals does not go to court and is settled through pre-trial agreements, the threat of reinstatement is always present, and it is the relevant constraint whose effects we analyse.

It is also important to stress how the labour code computes the 15 employees threshold relevant for Article 18, tutela reale. First of all, the 15 employees refer to establishments rather than to firms, and to different establishments as long as they are located within the same city. In addition, the 15 employees refer to the date in which the firing was intimated, which can be ahead of the actual separation date. Further, apprentices and temporary workers below nine months should not be computed. Conversely, part-time workers should be included in proportion on to their actual time, and all other temporary contracts should be counted. Finally, any form of employment which does not classify as dependent employment (interim workers, full-time and part-time consultants) should not be included in the labour code based definition of employment. These measurement issues are relevant in the empirical strategy discussed in Section 4.

Notice that there are other relevant constraints that apply above a given threshold ${ }^{4}$. Firms employing more than 10 workers, are obliged to hire disadvantaged workers, which refer to officially registered long term unemployed. Further, as of 1999, firms employing more than 15 workers must employ disabled workers. ${ }^{5}$ Further, rules of the labour code linked to union related activity applies only to firms employing more than 15 employees. Such norms entitle workers to establish a firm level institution (Rappresentanze Sindacali Aziendali) that has the right to call general meetings, establish referendum, and post union related poster within the establishments. Also, firms with more than 15 employees have the right to vote for a worker representative for safety related issues. Finally, since 1991 collective dismissals procedures are in place above the 15 employees threshold. This procedure requires a credible risk of bankruptcy and requires the dismissal of at least 5 employees $^{6}$; it implies (long) negotiations with the union but does not generate further firing costs (or reinstatement risks) when implemented.

\footnotetext{
${ }^{3}$ Notice that this case is different from discriminatory dismissals (based on race, gender, political opinions for example), where reinstatement is automatic and independent of firm size.

${ }^{4}$ These thresholds are computed according to rules that are somehow different from those relevant for Article 18 detailed above.

${ }^{5}$ As we discuss in section 4, our dataset refers to the period 1987-1996, so those mandatory rules on disabled workers are not binding in our time period.

${ }^{6}$ Firms undergoing temporary crisis may access supplementation schemes instead of firing part of their workforce; wages are temporarily paid by supplementation funds and the employment spell in not broken.
} 


\section{A Toy Model of EPL with Threshold Effects}

EPL is traditionally modelled as a firing tax on labour shedding, and the original theoretical framework is the dynamic labour demand under uncertainty. Bentolila - Bertola (1990) characterize the optimal employment strategy of a monopolistic firm subject to idiosyncratic shocks and firing costs, holding wages fixed. Most of this literature takes EPL as given, and looks at the employment effect of different degrees of job security provisions. A very simple exposition of the Bertola-Bentolila model is the one of Schivardi (2000). To the best of our knowledge, there are no explicit models that derive employment predictions when EPL is binding only for firms larger than a given size. In this section, we build on the work of Schivardi (2000) and Bertola (1999), and introduce threshold effects in a toy model of labour demand. This section proceeds as follows. First, we solve for the efficient allocation, next we show the properties of the model with an extreme form of EPL. Finally, we introduce threshold effects, and derive the main empirical predictions on firm level dynamics.

\subsection{The Set-Up of the Model}

We assume that there is a continuum of firms of mass 1, and that wages are exogenously fixed and equal to $w$. Each firm hires only labour and produces and sells a homogenous output with a convex production function $\mathrm{y}=f(\alpha$, $l)$, where $\alpha$ is a stochastic shifter of labor demand, $l$ is the quantity of labour employed, and $\square$ is a fixed-firm-specific parameter heterogeneous across firms. The shifter parameter $\alpha$ is an index of business conditions at each firm. It can take two different values, $\alpha=a_{b}$ in bad business conditions and $\alpha=\square$ (with $\square a_{b}$ ) in good business conditions. Firms are subject to an i.i.d. idiosyncratic shock and in each period there is a probability $p$ that business conditions are good and a probability (1-p) that business conditions are bad. The parameter $\square$ differs across firms, and is distributed according to the distribution function $F(x)=\operatorname{Prob}(\square=x)$, where $\mathrm{F}$ is continuous with no point mass and defined over the support $\Omega \square\left[\mathrm{a}_{\mathrm{b}}, \mathrm{a}_{\mathrm{g}}^{\max }\right]$. This implies that firms are identical when business conditions are idiosyncratically bad, while differ in their profit schedule when business conditions are good. Since firms differ only for their idiosyncratic parameter $\square$ in what follow we index firms simply by $\square$ Firms are dislocated in islands, there is no entry or exit and profits exist in good and bad times as long as $a_{b}>w$. In this respect, the analysis is left at the partial equilibrium level. The model is stationary and we do not need to explicitly keep track of the time index $t$, even when we introduce EPL. If the production function is quadratic in labour, firm's profit for a type- $\square$ firm can be written as

$$
\Pi(\alpha, \varepsilon, l)=\alpha l-\frac{1}{2} l^{2}-w l
$$

where

$$
\alpha=\left\{\begin{array}{l}
a_{b} \text { with probability } p \\
\varepsilon \text { with probability }(1-p)
\end{array}\right.
$$




\subsection{The Efficient Allocation}

Assume now that each type- $\square$ firm can choose the optimal employment level after observing the realization of the shock $\alpha$, and assume that hiring and firing can take place at no cost. Firm optimal employment behaviour is obtained simply by maximizing profits in each period, so that the firm continuously set the marginal product equal to the wage, or

$$
l *(\varepsilon)= \begin{cases}l_{b}=a_{b}-w & \text { if } \alpha=a_{b} \\ \lg (\varepsilon)=\varepsilon-w & \text { if } \alpha=\varepsilon\end{cases}
$$

This implies that a type- $\square$ firm, in steady state, spends a fraction $p$ of its time in bad business conditions with $l^{*}=l_{b}$ and a fraction $(1-p)$ in good business conditions with $1^{*}=l_{g}(\square$, where the star symbol refers to the efficient allocation. In this situation firms shed all labour in excess of $l_{b}$ when business conditions turn bad and hire up to $\mathrm{l}_{\mathrm{g}}(\square)=\square \mathrm{w}$ when business conditions turn good. Expected profits for a type- $\square$ firm are

$$
E \Pi *(\varepsilon)=\frac{p}{2}\left[a_{b}-w\right]^{2}+\frac{(1-p)}{2}[\varepsilon-w]^{2} .
$$

Profits are obviously increasing in $\square$

\subsection{The Rigid System}

Assume now that EPL is so strict that firing is impossible. A type- $\square$ firm will then choose a level of employment that maximizes average profits, and will keep its employment constant at all time. In other words, a type- $\square$ firm will choose a level of employment to maximize average expected profits

$$
\Pi^{R}(\varepsilon, l)=p\left(a_{b} l-\frac{1}{2} l^{2}-w l\right)+(1-p)\left(\varepsilon l-\frac{1}{2} l^{2}-w l\right),
$$

where $\square^{\mathrm{R}}(\square, l)$ are the profits for a type- $\square$ firm in the rigid system. If we indicate with $l^{R}(\square)$ the result of the maximization, its expression reads

$$
l^{R}(\varepsilon)=p a_{b}+(1-p) \varepsilon-w .
$$

Confronting the rigid and the efficient allocation, an important implication immediately follows.

Result 1. Average employment for a type- $\square$ firm in the efficient and in the rigid allocation is identical. The result is obtain by simple inspection of $l^{R}(\square)$, which can be written as $l^{R}(\square)=p\left(a_{b}-w\right)+(1-$ $p)(\square-w)$. But then $l^{R}(\square)$ is the average level of employment of a type- $\square$ firm in the efficient allocation. Further, profits are larger in the efficient allocation, as long as $p$ is different from 0 and 1 . To obtain the latter result simply observe that profits in the rigid system are

$$
\Pi^{R}(\varepsilon)=\frac{1}{2}\left[p a_{b}+(1-p) \varepsilon-w\right]^{2}
$$

which is an expression that is always lower than $E \square *$ as long as $p$ is strictly positive and less than one. In addition, one can also observe that firm employment in the rigid system is less volatile than in the efficient allocation, since firms never hire and fire. These results are the standard implications of the 
EPL literature with fixed wages, and are just reported for introducing threshold effects, on which we turn next ${ }^{7}$.

\subsection{The Role of Threshold Effects}

Assume now that the rigid regime is enforced only for employment level larger than $l^{\text {thr }}$, where $l^{t h r}$ is an exogenous threshold specified by the legislation. The only restriction we impose is that $l^{t h r}>a_{b^{-}}$ $w$, otherwise the problem is not even interesting. In this setting, once a firm grows beyond the employment level $l^{\text {thr }}$ firing becomes impossible, while it can take place at no cost for employment levels less or equal than $l^{t h r}$. With threshold effects, some type- $\square$ firms have the option to permanently fluctuate in the flexible fringe of the firm size distribution, or in the interval $1\left[\left[l_{b}, l^{\text {thr }}\right]\right.$, where $\mathrm{l}_{\mathrm{b}}$ is the efficient level of employment when business conditions are bad. We label these type of firms as "scared firms", and their formal definition follows.

Definition SCARED FIRM: A type- $\square$ firm with efficient employment allocation in good business conditions larger than the threshold $\left(l_{g}(\square)>l^{\text {thr }}\right)$ is scared when it employs $l=l_{b}$ in bad business conditions and $l=l^{\text {thr }}$ in good business conditions. Thus, a scared firm never passes the threshold, shed labour up to $l_{b}$ when business conditions turn bad, and hire up to $l^{\text {thr }}$ when business conditions are good, and features average employment level $1^{\mathrm{SC}}=p l_{b}+(1-p) l^{t h r}$. A scared firm follows a stay-smallpolicy, since in good times is reluctant to grow beyond the threshold. Expected profits of a scared firm are

$$
\Pi^{S C}(\varepsilon, l)=p\left(a_{b} l-\frac{1}{2} l^{2}-w l\right)+(1-p)\left(\varepsilon l-\frac{1}{2} l^{t h r 2}-w l^{t h r}\right)
$$

while its employment behaviour is

$$
l^{S C}(\varepsilon)= \begin{cases}l_{b}=a_{b}-w & \text { if } \alpha=a_{b} \\ l_{\mathrm{g}}=l^{t h r} & \text { if } \alpha=\varepsilon\end{cases}
$$

so that the average level of profits is

$$
E \Pi^{S C}(\varepsilon)=\frac{1}{2} p\left(a_{b}-w\right)^{2}+(1-p)\left(\varepsilon l^{t h r}-\frac{1}{2} l^{t h r^{2}}-w l^{t h r}\right)
$$

With threshold effects, some firms have to choose between a rigid allocation and a stay small policy. In the former case they have an employment base larger than the threshold, they permanently employ $l^{R}(\square)$, and never fire. In the latter case, they permanently fluctuate inside the flexible fringe of the size distribution.

To complete our description, we need to characterize the conditions that insure that scared firms exist in equilibrium. In general, a type- $\square$ firm will be scared and will follow a stay small policy as long as its average profit are higher than the average profits from the rigid system, or when $E \square^{S C}(\square)>E \square^{R}(\square)$. Among other things, this condition clearly depends on the specific value of the idiosyncratic parameter $\square$ as we show in our next result.

\footnotetext{
${ }^{7}$ While the model holds wage fixed, the results of modelling EPL as a tax on labour shedding do not change in models with endogenous wage as long as EPL is modelled as a tax. See Garibaldi - Violante (2002).
} 
Result 2. Firms in the interval $\left.\square \square^{*}, \square^{* *}\right]$ are scared, where $\square^{*}=l^{t h r}+w$ and $\square^{* *}$ is a positive number larger than $\square^{*}$. In light of this result, the firm size distribution is partitioned in three intervals. Firms with idiosyncratic component $\square$ lower than $\square^{*}$ are totally efficient and do not interact in any way with the threshold (their employment level in good times is lower than the threshold). Firms with idiosyncratic component in the interval $\left[\square^{*}, \square^{* *}\right]$ are scared, and in good times bunch with employment $l^{t h r}=\square^{*}-\mathrm{w}$. Finally for idiosyncratic values of $\square$ larger than $\square^{* *}$, firms are rigid and hire $l^{R}(\square)$.

Proof. To prove this result one needs simply to introduce the function $\mathrm{z}(\square)=\square^{S C}(\square)-\square{ }^{R}(\square)$ whose expression reads

$$
z(\varepsilon)=\frac{p}{2}\left(a_{b}-w\right)^{2}+(1-p)\left(\varepsilon l^{t h r}-\frac{1}{2} l^{t h r^{2}}-w l^{t h r}\right)-\frac{1}{2}\left[p a_{b}+(1-p) \varepsilon-w\right]^{2}
$$

First note that the threshold is irrelevant for those firms for which $l_{g}(\square)<l^{\text {thr }}$, which is a condition that is satisfied as long as $\square<\square^{*}$, with $\square^{*}=l^{\text {thr }}+w$. Type- $\square$ firms with idiosyncratic component below $\square^{*}$ are totally efficient and do not interact in any way with the threshold.

Second, note that $z\left(\square^{*}\right)=1 / 2 p(1-p)\left[a_{b}-w-l^{\text {thr }}\right]^{2}>0$ and that $z^{\prime}\left(\square^{*}\right)>0$ so that firms with $\square>\square^{*}$ are certainly scared. To find the upper support of the interval $\left[\square^{*}, \square^{* *}\right]$ one needs to solve the quadratic equation $z(\square)=0$ whose largest root reads ${ }^{8}$

$$
\varepsilon * *=\frac{\varepsilon^{*}-\sqrt{p} a_{b}}{1-\sqrt{p}}
$$

It is immediate to see that $\square^{* *}>\square^{*}$ strictly, so that all firms in the interval $\left[\square^{*}, \square^{* *}\right]$ are scared. Conversely, for $\square \square^{* *} z(\square)<0$ and firms choose the rigid system.

An important result easily follows.

Result 3. A type- $\square$ firm that is scared has average employment level that is lower than the average employment level in the efficient allocation and in the fully rigid system.

Proof. From Result 2 and from the definition of scared firms it follows immediately that $l_{g}(\square)>l^{\text {thr }}$ for all $\square\left(\square^{*}, \square^{* *}\right]$ where $l_{g}(\square)=\square-w$. Since $l^{R}(\square)-l^{S C}(\square)=(1-p)[\square \square *]$, it is obvious that all scared firms with $\square\left(\square^{*}, \square^{* *}\right]$ feature average employment that is lower than the average employment in the rigid system.

This result is important, since it shows that one of the standard predictions of traditional EPL models, namely result 1 , does no longer hold when scared firms exist. Result 3 is further summarized by looking at Figure 1, where we report the optimal employment level for a type- $\square$ firm under three regimes: the efficient allocation, the rigid system, and a stay small policy. Points A and B in the figure refer to the employment level under the efficient allocation, when the firm switches its employment level between $1_{\mathrm{b}}$ and $\mathrm{l}_{\mathrm{g}}(\square)$. Point $\mathrm{C}$ refers to the employment level under the rigid system, and $l^{R}(\square)$ is the amount of labour that the firm permanently employs, independently of business conditions. When a firm is scared, its employment level shifts between point $\mathrm{A}$ in bad times and point $\mathrm{D}$ in good times. Clearly, the average between A and D is lower than the employment level associated to point C.

[Figure 1 APPROXIMATELY HERE]

\footnotetext{
${ }^{8}$ Note that in the quadratic equation $z(\square)=0$ there are two positive roots, but the smallest one is lower than $\varepsilon^{*}$ and is economically meaningless, since for values of $\square<\varepsilon^{*}$ firms are totally efficient and can not be scared.
} 


\subsection{Threshold Effects and Reality: Two Empirical Predictions}

The main results of our theoretical model, namely that average employment is affected by size contingent EPL, under conditions that would make it independent of uniform EPL provisions is new in the literature, and would hold under more general models. The general intuition is as follows. A size contingent EPL introduces more flexibility in the firms' dynamic optimization problem, and such flexibility is going to be exploited in equilibrium by profit-maximizing firms. Specifically, firms close to the threshold face a trade-off between dynamic efficiency (the possibility of adjusting their size in response to future shocks) and average long-run size, which in our model is proxied by the idiosyncratic parameter $\square$ Our main result shows that there exists a well defined mass of firms that solve such trade-off in favour of dynamic efficiency, at the expense of a smaller average long run size. Obviously, such trade-off does not arise in the case of a uniform EPL provision, and all firms are obliged to solve the trade-off in favour of the larger average long-run size option.

Real life firms are obviously much more complicated than the firms described in the toy model, since they differ in many dimensions beyond the single parameter $\square$ Moreover, it would be quite difficult to find an empirical counterpart to the idiosyncratic parameter $\square$ which in reality may represent technological, managerial as well as demand factors. One may certainly try to write down a model that keeps track of all such dimensions, and properly calibrate the size distribution of firms. But that is neither the purpose of our model, nor the purpose of the paper, which is mainly empirical.

In what follows, we restrict the attention to the employment level around the threshold, where our model suggests that three type of firms coexist: i) firms whose long run position in good times is below the threshold, and have no interest in growing beyond the threshold; ii) firms that are growing beyond the threshold toward the no flexible regime and iii) scared firms that are reluctant to hire. Beyond the threshold, flexible and scared firms disappear. Since scared firms are likely to be stuck before the threshold, a key prediction of our analysis is the following persistence prediction, where the threshold refers to the 15 employees threshold of the Italian labour code.

Persistence Prediction: firm level persistence in employment dynamics increases right below the threshold;

While the persistence prediction is our key prediction, at least another prediction can be derived. At the threshold, scared firms face a probability $p$ of reducing their employment base, while they have no chance of increasing their size. There is a key asymmetric behaviour. To derive a clear prediction in this respect, assume that each firm is characterized by more than two levels of the shifter parameter $\varepsilon$, so that firms have more than two possible employment states. Then, it is clear that scared firms at the threshold will not react to small shocks that would increase their employment level, while they certainly react to negative shocks. This leads to our second prediction.

Asymmetric Prediction: Firms at the threshold should respond asymmetrically to positive and negative employment shocks, and react more markedly to negative than positive shocks.

While our focus is mainly on the effects of the EPL threshold, we should recall that in reality there are other institutions that may affect employment dynamics around the 15 employees. The 
requirement to hire specific categories clearly imply an increase in average labour costs. The same effect should be played by the presence of union related institutions, since beyond the threshold a subset of the workers can spend paid time in off production activities. In both cases, the increase in labour costs should reduce labour demand, and slow down employment growth.

Finally, we should recall that our model and our predictions are only relevant when EPL takes the form of a firing tax. Lazear (1990) has shown that a pure severance payment with flexible wages has no allocative impact on the labour market. Nevertheless, the reinstatement clause of the article 18 of the labour code is more akin to a tax than to a transfer, so that the predictions spelled out above appear appropriate.

\section{Empirical Analysis}

\subsection{Data and Empirical Strategy}

The empirical goal of this paper is to study employment dynamics of firms close to the 15 employees threshold, and to check whether such behaviour is consistent with the theoretical predictions outlined above. This empirical exercise can be done successfully only using longitudinal microdata on employment.

The existing literature, albeit scant, does not find any significant evidence of threshold effects. Anastasia (1999) studies the firm size distribution in the Italian economy and in Veneto (a large Italian region), and does not find any significant bunching of firms close to the threshold. Tattara (1999) focuses on two provinces of the Veneto region, and does not find any significant threshold effect on accession and separation rates of workers, as well as on the probability of growing/shrinking of firms when this implies crossing the 15 employees threshold. Istat (2002), in its recent annual report, looks at the firm size distribution, and finds a very small bunching of firms at 15 employees. With respect to those studies, the present paper emphasizes the effects of EPL on firm inaction and asymmetric behaviour around the threshold, two dimensions that have not been analysed yet.

\subsubsection{Data Description}

Our data are drawn from the Italian Social Security Administration (INPS) archive of firms ${ }^{9}$. The archive includes the population of private Italian firms that have at least one employee. It is a rolling panel and, for each firm, it records the monthly total number of employees over 6 years. From this INPS archive we extract a series of cross-sections of firms for the period 1987-1996 as follows; in a given year $t$, we select all firms that in May $t$ employ a worker born on the 10th of March, June, September or December. For sampled firms at year $t$, we keep information only on the employment stock in December of year $t$ and $t-1^{10}$. This generates in each year a random sample of firms,

\footnotetext{
9 "DM10m, record normalizzati". We exclude from the records agricultural and public sector firms whose social security records are administered by INPS.

${ }^{10}$ In terms of age, our sample requires firms to have at least one year of life, while it is perfectly possible that firms currently active leave the market in the following year.
} 
representative of the population; the sampling probability being $1 / 90^{11}$ times the size of the firm in May $t$. Note that a firm sampled in year $t$ will be sampled in year $\mathrm{t}+1$ if and only if it still employs a workers born in the specified dates.

We drop firms above 30 employees, so that the 15 employees threshold lies perfectly in the middle of our size interval. Every year, the sample includes some 900 firms of 14, 15 or 16 employees. Controlling for size classes (1-5, 6-9, 10-19 employees), our sample matches very closely the distribution of firms in the population by other dimensions, as published by the INPS Observatory ${ }^{12}$. For example, the distribution of firms by branch in our sample and in the population is almost exactly identical. We obtain the same result by geographical area (north-west, north-east, centre, south). This is an indication in line with a random draw from the relevant population.

As we mentioned above, the sampling probability is not constant, but it is proportional to the size of the firm. This can be seen by comparing the distribution of firms in our sample to that of the INPS Observatory. While our sample consists of some 5 percent of the total firms in the Italian economy, it clearly under-samples very small firms. In Table 1 we report the ratio between our firms and the number of firms in the INPS Observatory. Such ratio increases from some 2 percent for the 1-5 employees category to 12 percent for firms in the 10-19 employees categories. The over weight in the sample given by large firms can be seen also in Figure 2, where we report the proportional number of firms between 10 and 20 employees in our sample and in the ASIA archive, the register of all active Italian firms. Notice that the sampling ratio increases smoothly over size.

\section{[Table 1 APPROXIMATELY HERE]}

[Figure 2 APPROXIMATELY HERE]

\subsubsection{Empirical Methodology}

We proceed in two steps. The first step uses data at the firm level to estimate transition probability matrices, while the second step uses the estimated transition probabilities.

In the first step we use the cross sections of firms to estimate a set of transition matrices for employment size. As we said above, we concentrate on firms with employment in the interval $[i=1$, $\mathrm{I}=30]$. We let $n_{i, t}$ be the number of firms that employ $i$ workers at time $t$ and $n_{i j, t+1}$ the number of firms of size $i$ at $t$ that employ $j$ workers in $t+1$. We then estimate the following set of transition probabilities

$$
p_{i j, t}=\frac{n_{i j, t+1}}{n_{i, t}} \ldots . . i=1 \ldots . . I
$$

where $p_{i j, t}$ represents the maximum likelihood estimator of the underlying transition probability. When $i=j$, the transition probability refers to the persistence probability, or the probability of employment inaction. Since there are $T+1$ years in the sample (i.e. 10 years from 1987 to 1996), and $I$ size categories, the previous estimate generates a dataset of $\left(I^{*} I^{*} T\right)$ observations ${ }^{13}$, in which the

\footnotetext{
${ }^{11} 1 / 90$ because we select 4 days of birth out of 365 .

${ }^{12}$ The yearly report published by the Social Security Administration; it is the official source of statistics on the population of firms covered by INPS. Size classes in the INPS Observatory are those reported, followed by 20-49, 50-99 employees, etc. Unfortunately neither 15 nor 30 employees define a class.

${ }^{13}$ I.e. $30 * 30 * 9=8100$ observations.
} 
representative observation is just $p_{i, t}$ or the estimated probability that a firm of size $i$ switches to size $j$ in $t+1^{14}$.

The second step uses transition matrices to test whether employment dynamics around the 15 employees threshold is consistent with the theoretical predictions. We perform tests on employment persistence and on asymmetric behaviour. The spirit of the tests we perform is as follow. First, we fit a parametric relationship linking the transition probabilities to firm size. Second, we test whether the transition probability around the threshold is an outlier vis-à-vis the estimated parametric relationship.

Before specifying the details of our methodology, two preambles are needed. First, an alternative empirical strategy would be to estimate an employment growth equation at the firm level. In the literature, several Gibrat law type of models have been proposed, although to the best of our knowledge none of them addresses the threshold effect we are focussing on. ${ }^{15}$ We choose the transition matrix approach for three reasons: its interpretation is in line with our theoretical predictions; its econometric approach is relatively simple; it fits well with the structure of our dataset (repeated cross sections). Second, our relatively short-time dimension does not allow us to study the cyclical behaviour of firms. Further, our data set does not allow us to disaggregate along other dimension the transition matrices we estimate, since such dis-aggregation would significantly decrease the number of firms in each cell of the transition matrices. The only breakdown we can do is to split the sample in manufacturing and service sector. We next turn to the specification of the test on the persistence and on the asymmetric behaviour.

\subsubsection{Persistence Test}

If we indicate with $p_{i i, t}$, the estimate of the persistence probability for firms of size $\mathrm{i}$ between time $t$ and $t+1$, our first step requires estimating the following baseline regression

$$
p_{i i, t}=\gamma_{t}+\alpha f\left(\text { size }_{i}\right)+u_{i t}
$$

where $f\left(s_{i z e_{i}}\right)$ is a (possibly non-linear) function of $s_{i z e}$, and $\gamma_{\mathrm{t}}$ is a time effect. Let $\delta_{j}$ be a dummy of window $m$, or a dummy variable that takes the value 1 if size belongs to the interval $[j-m, j+m], m=0,1$. We then estimate the following regression

$$
p_{i i, t}=\gamma_{t}+\alpha f\left(\text { size }_{i}\right)+\delta_{j}+u_{i t}
$$

for various values of $\delta_{j}$. The persistence test is equivalent to the following test

$$
H_{0}: \delta_{j}=0 \quad H_{1}: \delta_{j}>0 ; j=13,14,15
$$

which is simply a test that looks for an increase in $p_{i i, t}$ around the 15 employees threshold. This type of test needs to be carried out with different baseline statistical models, and several robustness tests in terms of the size of the dummy.

\footnotetext{
${ }^{14}$ Notice again that our transition probabilities refer only to continuing firms. In section 4.3, we look at entry and exit behaviour, and we show that there is no evidence of irregular exit patterns around the threshold.

${ }^{15}$ See Sutton (1997) and references therein for a survey of Gibrat's law literature.
} 
To estimate this model we use a subset of the I*I*T matrix; we select only the elements in the main diagonal, and obtain an $\mathrm{I}^{*} \mathrm{~T}$ matrix. Notice also that we include only one size dummy in each estimated model, i.e. we estimate the same model several times including size dummies in turn:

$$
\begin{aligned}
& p_{i i, t}=\gamma_{t}+\alpha f\left(\text { size }_{i}\right)+\delta_{14}+u_{i t} \\
& p_{i i, t}=\gamma_{t}+\alpha f\left(\text { size }_{i}\right)+\delta_{15}+u_{i t} \\
& p_{i i, t}=\gamma_{t}+\alpha f\left(\text { size }_{i}\right)+\delta_{16}+u_{i t} \\
& \text { and so on. }
\end{aligned}
$$

While the previous test can highlight the existence of outliers close to the threshold, it ultimately relies on the parametric estimate of a statistical model which is not directly derived from the underlying economic analysis. In a more non parametric fashion, one can perform a bootstrapping exercise for estimating the standard deviations of the probabilities in the original transition matrices. More specifically, we bootstrap $k$ samples of size $n$, where $n$ is the number of firms used to estimate the transition probability $p_{i i, t}$. With the $k$ samples in hand, we estimate the standard deviations, and construct confidence intervals of our persistence probability. We perform this exercise separately for each year. $^{16}$

\subsubsection{Asymmetric Behaviour Test}

Let pdiff $_{i k t}$ be the difference between the probability of increasing and decreasing firm size by $k$ positions, so that pdiffikt reads $p$ diffikt $=p[i, i+k], t-p[i, i-k], t$, where $p_{[i, i+k], t}$ and $p_{[i, i-k], t}$ are the probabilities of moving from size $i$ to size $i+k$ and to $i-k$ respectively. In other words, $k$ is the size of the off-diagonal jump that we consider. If $k=1$, pdiff ikt $_{t}$ is just the difference between the probabilities alongside the main diagonal. We focus on $\operatorname{pdiff}_{i l t}$ and $p \operatorname{diff}_{i 2 t}$ only, as off diagonal observations decline sharply as $k$ increases, worsening the precision of the maximum likelihood estimate of $p_{i j t}$. We then estimate a new baseline regression of the form

$$
\text { pdiffikt }_{i}=\gamma_{t}+\alpha_{1} f\left(\text { size }_{i}\right)+u_{i t}
$$

If $\delta_{j}$ is the dummy defined in the previous paragraph, we run a set of regressions for different size dummies $\delta_{j}$

and we test the following assumption

$$
p d i f f_{i k t}=\gamma_{t}+\alpha_{1} f\left(\operatorname{siz} e_{i}\right)+\delta j+u_{i t}
$$

$$
H_{0}: \delta_{j}=0 \quad H_{1}: \delta_{j}<0 ; j=14,15
$$

so that at the 15 employees threshold, the probability of moving down by one or two positions is larger than the probability of moving up by one or two positions. The same approach followed in estimating model [3] is applied here: we select $\mathrm{I}^{*} \mathrm{~T}$ differences in transition probabilities and we include size dummies in turn, as detailed in equations [5] to [7].

\footnotetext{
${ }^{16}$ Pooling transition matrices over time might generate correlation over time of $p_{i i, t}$ and bias the results of the bootstrap procedure.
} 


\subsection{Strategic Behaviour and Measurement Issues}

Before proceeding to discussing the results of our analysis, we should realize that firms may take strategic behaviours aimed at avoiding the implementation of the constraint imposed by the law. The dataset we exploit, although rich and detailed in many respects, does not allow us to control for various possibilities, which we discuss next. Specifically, we face three different problems.

First, suppose that a firm reaches 16 employees and wants to avoid the institutional constraint; it may divide the firm in two new distinct legal entities of less than 15 employees that do not satisfy the requirements imposed by the labour code. All we can do in this respect is using data on entry and exit of firms to check whether firm exit before the threshold is particularly high, suggesting that firms exit before the threshold, just for re-enter the labour market with two different entities below the threshold. A close check on this point shows that average entry and exit rates by firm size decline sharply by firm size, but do not experience any clear pattern around the threshold ${ }^{17}$. Yet, our methodology and our results do not exclude the existence of other, more sophisticated, strategic actions aimed at eluding the EPL threshold. For example, a firm may split its activity in two different plants located in different cities when it reaches the 15 employees threshold. This is relevant since in the labour code the 15 employees must be hired within the same cities. However, this action is likely to be more costly than facing the EPL provisions.

Second, our dataset refers to firms, while the threshold rules specified in the labour code refer to establishments. Statistics on the distribution of multiplant firms by size are not easily available; in general small firms are likely to be single establishment firms ${ }^{18}$. Hence, these discrepancies should not dramatically affect our results.

Third, firms close to the threshold may start hiring categories of workers that are not counted in the labour code definition of employment (consultants, apprentices, interim workers). Further, firms close to the threshold may increase the incidence of irregular employment and hire the marginal workers as shadow employees. In these cases, the existence of an EPL threshold has modified firm's employment dynamics, but only a longitudinal dataset that follows the firm across all these dimensions would be able to identify these effects. Our main dataset records only total dependent employment (without distinguishing for apprentices and temporary workers). Nevertheless, we can use a different INPS dataset recording firms located in Turin only (an industrialized province in the North West) from 1990 to 1992 to perform a more detailed analysis. Such dataset distinguishes between apprentices, trainees, and part timers, and allows us to measure the 15 employees relevant for the labour code. We will present the results using this richer dataset (albeit geographically not representative) as a robustness check to the empirical analysis for the entire Italian economy.

\footnotetext{
${ }^{17}$ In addition, the observation on entry and exit suggests that our focus to continuing firms should not give us obvious problems vis-à-vis the tests that we provide.

${ }^{18}$ See also Contini (2002).
} 


\subsection{Econometric Issues}

Since our sampling strategy is proportional to firm size, the precision of the maximum likelihood estimates of the transition probabilities increases with firm size. One may argue that since in our regressions size (or a function of it) is a regressor, this may lead to biased OLS estimates. While this may be partially true, what we want to find is the threshold effect around the 15 employees, and our sample coverage increase smoothly with firm size, as clearly reported in Figure 2. Since we are mainly interested in the specific effect of moving from 15 to 16 employees, we do not expect any systematic error on this part of the estimates. In other words, we do not see why these problems should be correlated to the 15-employees threshold.

As it is clear from the discussion above, we estimate a transition matrix for each year in our sample, so that our panel data is obtained by pooling over time these different transition matrices. In light of our sampling construction, a similar pool of firms may contribute to the estimate of the cell $(k, j)$ of the transition matrix in different years. Since this effect may introduce time correlation in our estimated probabilities, all the results we report refer to robust standard errors, that allow for correlation over time of probabilities referred to the same size class.

Finally, we use OLS when our dependent variable lies between zero and one. This forbids to use predicted values, as they may lie outside the acceptable range, but it does not bias our estimates.

\section{Results}

Table 2 reports the estimate of the time average transition matrix for our sample of firms. In the table we report the estimate of the average diagonal element, $p_{i, i}$ as well as the average value of the two off diagonal terms close to the main diagonal, namely $p_{i, i+1,}, p_{i, i+2}$ and $p_{i, i-1}, p_{i, i-2 .}$. Few comments are in order. First, the persistence probability declines smoothly with firm size. Second, for the smallest firm size categories the probability density is concentrated around the main diagonal. Larger firms, conversely, have also a sizable probability of changing their employment size by several employees. Third, the probability of increasing and decreasing by one position declines also as a function of size. All this should not be surprising, since the relative employment weight of an extra employee (hired or fired) declines dramatically with firm size.

\section{[Table 2 APPROXIMATELY HERE]}

Figure 3 reports the implied long-run distribution obtained from the average transition matrix in Table 2. Clearly, the long-run distribution features a smooth monotonic shape, in a way similar to the empirical distribution observed in the actual data. In particular, the empirical distribution does not feature a dramatic bunching of firms at size 15 . Nevertheless, the figure suggests a "small turbulence" in the neighbourhood of the threshold, since the long-run number of firms at size 15 is as large as the number of firms at 14 employees. Remarkably, Istat (2002) in its recent annual report, observed a similar small "turbulence" relatively to the 1999 firm size distribution. This is particularly reassuring for our analysis, since we use a dataset of only 5 percent of firms, and our implied long run distribution ignores the role of entry and exit. We now move to our tests.

[Figure 3 APPROXIMATELY HERE] 


\subsection{Persistence Effects}

Figure 4 reports the estimates of the persistence probability by firm size over the period 19871995. The Figure reports the estimates for different years, and shows that the dispersion around the median (solid line) is relatively small for the spike at the 15 employees. This small deviation is quite important, since it increases the probability of rejecting the persistence test. The Figure highlights two spikes in the persistence probability, one at 15 employees and one at 20 employees. The first one is the spike we are looking for, since it appears exactly at the EPL threshold imposed by the Italian legislation. We have no obvious explanation for the 20 employees spike, as heaping at round numbers is not a likely event in administrative archives ${ }^{19}$.

\section{[Figure 4 APPROXIMATELY HERE]}

After looking at Figure 4, an obvious model candidate for our test is a linear regression in which the persistence probability is regressed on the inverse of size so that

$$
p p_{i t}=\gamma_{t}+\frac{\alpha}{\text { size }_{i}}+u_{i t}
$$

where the regressor $1 /$ size captures the underlying smooth relationship between the persistence probability and firm size. Figure 5 reports the solid line of Figure 4 and the benchmark statistic relation estimated according to equation [11]: the persistence probability increases close to the threshold, and declines thereafter. Table 3 (in the column labelled Model 1) reports the estimated coefficients obtained by adding size-one dummies in turn to the model outlined above. The dummy is positive and strongly significant already at size 13, and reaches a peak at size 15, with a quantitative value that is about 2 percent. When the size of the dummy is 3 (column labelled Model 2), the results do not change much.

Figure 6 reports the residuals from the baseline model, and shows that the residuals below the threshold are consistently positive. On the one hand, one can argue that such pattern is exactly what the theory would predict, since firms below the threshold anticipate the effect. On the other hand, one can argue that the baseline model is not properly estimated, and it is necessary to reduce the bunching of positive residuals below the threshold. In this respect, we also run a baseline regression in which the size variable enters both in linear and non linear terms, so that

$$
p_{i t}=\gamma_{i}+\frac{\alpha}{\text { size }_{i}}+\beta \text { size }_{i}+u_{i t}
$$

While Figure 7 shows that the residuals are now more randomly distributed around zero in the baseline model, the threshold effect is still present, as highlighted by the results of Table 3 (columns labelled Model 3 and 4). This holds with dummies both of size 1 and 3, and the results are quite similar if the analysis is restricted simply to the manufacturing or the service sector (results are not reported). Model 3 highlights also a negative and strongly significant dummy at size 16 and 17 (lower persistence probability with respect to the baseline model) consistent with the theoretical predictions. Overall, the evidence provided suggests that, on average, firm persistence below the threshold increases by some 1.5 percent relatively to a baseline specification.

\footnotetext{
${ }^{19}$ However, while the spike at 15 employees is quite robust to different estimation methods, the one at 20 is not.
} 
[Table 3 APPROXIMATELY HERE]

[Figure 5 APPROXIMATELY HERE]

[Figure 6 APPROXIMATELY HERE]

[Figure 7 APPROXIMATELY HERE]

From the discussion above it comes out a clear change of regimes at the 15 employees threshold. We can infer from this that the threshold is quite well measured, or that measurement errors discussed in section 4.2 do not bias the econometric analysis of the estimated transition probabilities. In fact, if measurement errors were important, we would observe a grey area around the 15 employees threshold. The next section addresses this point further.

\subsection{Persistence Effects: Further Robustness Tests}

We perform two different robustness checks on the persistence effect. We try a non parametric approach (see section 4.1.1) and a correction of the measurement error in the number of employees that is relevant for the labour code (see section 4.2).

First, it is possible to estimate non parametrically the standard deviations of the transition probabilities. This is done in Table 4, where we report the results of the bootstrapping of 500 samples from our original transition matrix 1994-1995, following the procedure described in Section 4.1.1. Notice that results are unchanged increasing the number of draws or selecting different years. The Table reports the standard deviation and the lower and upper tail of a 95 percent confidence interval around the mean, where the confidence intervals are obtained either by assuming a normal distribution of the mean of the various samples or using bootstrapped $5^{\text {th }}$ and $95^{\text {th }}$ percentiles corrected for the eventual bias in the bootstrapped mean. Table 4 shows that the 1994-1995 persistence probabilities are decreasing as firm size increases, with the exception of $p_{15,15}$ that is higher and of $p_{16,16}$ that is lower than the neighbouring $\mathrm{p}_{\mathrm{i}, \mathrm{i}}$. Considering the bootstrapped $95 \%$ confidence interval we obtain that $\mathrm{p}_{\mathrm{i}, \mathrm{i}}$ is non significantly different from $\mathrm{p}_{\mathrm{i}-1, \mathrm{i}-1}$ and from $\mathrm{p}_{\mathrm{i}+1, \mathrm{i}+1}$ for all firm sizes with the exception of the couple $\mathrm{p}_{15,15}$ and $\mathrm{p}_{16,16}$. These two are significantly different. We interpret the result as non parametric evidence of the spike at 15 employees of the persistence probability.

[Table 4 APPROXIMATELY HERE]

Second, the definition of employment relevant for the labour code is slightly different from the total dependent employment observed in our main sample. The labour code computes 15 employees based on specific definitions, which exclude some employment categories such as apprentices and temporary workers below 9 months. This implies that our total employment variable overestimates the effective threshold, since it includes employment categories that are excluded from a labour code standpoint. While for the overall Italian sample we can not distinguish among different employment categories, and we have to rely on the total dependent employment variable, fortunately, we are able to reconstruct the definition of employment relevant for the labour code for the Turin province, a highly 
industrialized area in the North, for the period 1990-1992. This is an important robustness test, since it gives us the possibility of estimating the difference between the two employment measures.

The results based on the Turin province are reported in Figure 8 and Figure 9. An immediate flavour of the importance of this problem can be given by the share of firms in which no difference between the two measures of size is recorded: $56 \%$. Figure 8 plots the mean difference between total employment and labour code based employment by firm size (based on total employment) in 1992, conditional on the difference being positive. It also plots the share of firms for which the difference is null, i.e. the share of firms that do not use any of the contracts non included in the threshold definition. Firms up to 15 employees hired an average measure two of labour non computed for the labour code. Such measure increases to 2.5 as firms cross the 15 employees threshold. Furthermore, beyond the 15 employees threshold there is a clear drop in the share of firms that do not make use of contracts excluded from the labour code definition of employment. Summing up, there is some evidence in favour of a strategic use of contracts to stay below the threshold.

The next question to address is how the use of non-standard (i.e. non dependent) employment contracts affect the test based on the transition probabilities? Figure 9 plots the average persistence probability of employment using the labour code based definition of employment and the total employment. Two observations are relevant. First, the two estimates of the persistence probability are very much correlated, with both variables experiencing a sizable threshold effect. Second, the size of the threshold effect appears more pronounced for the labour code based employment variable. This is exactly what one would expect. Furthermore, $p_{i i}$ drops at 16 employees using both the aggregate definition of size and the labour code based definition. The largest difference is observed at 12 and 13 employees, not right around the threshold. This is consistent with the fact that the analysis of the full dataset (discussed in the previous paragraph) shows a clear change of regimes at 15 employees. Hence, the characteristics we can highlight in Turin may be more general. Overall, these calculations suggests that the results obtained using total employment are similar to those obtained with a labour code based definition of employment, and that the behaviour of the two variables is highly correlated around the threshold.

\section{[Figure 8 APPROXIMATELY HERE]}

[Figure 9 APPROXIMATELY HERE]

\subsection{Asymmetric Behaviour}

To test the asymmetric prediction we need to work with the off diagonal terms of the transition matrix. Once we combine the probability of increasing and decreasing employment by one (two) positions, we obtain the variable $\operatorname{pdiff}_{i l t}\left(\operatorname{pdiff}_{i 2 t}\right)$, which is simply the net probability of growing by one (two) positions. This allows us to test the existence of asymmetric effects around the 15 employees threshold.

Figure 10 reports the actual and estimated relationship with size of the net probability of growing by one position $\left(\right.$ pdiff $\left._{i t}\right)$, and shows that there are several spikes along the size distribution. Among such spikes, two of them appear particularly large. The first is a positive spike at 14 employees, 
while the second is a negative spike at 15 employees. The latter spike is consistent with an asymmetric effect driven by the EPL threshold, since it suggests that firms employing 15 employees are more likely to move downward than upward. To further check on the asymmetric behaviour, Figure 11 reports the actual and estimated relationship with size of the net probability of growing by two positions (pdiffizt). Indeed, the spikes observed in Figure 10 at 14 and 15 employees should be observed here respectively at 13 (positive), 14 and 15 employees (negative). As Figure 11 shows, this appears to be case, providing further evidence of the asymmetric effect around the threshold.

Table 5 presents the detailed analysis of the asymmetry test, focusing on the net probability of growing by one position. It reports the value of the size dummies for a simple linear model estimated for the whole economy, as well as for the manufacturing and service industries separately:

$$
\text { pdiff }_{i 1 t}=\gamma_{t}+\alpha_{\text {size }}+u_{i t}
$$

Table 5 suggests that among the various outliers and spikes observed in Figure 10, the most important ones are the positive and negative spikes close to the threshold. When the transition probability refers to the whole economy, a firm with 15 employees features a decrease in the net probability of moving up by 1.5 percentage points relatively to the simple linear model. This effect increases to 2 percent if the analysis is restricted to the manufacturing sector, while is unchanged when referred to the services. The effect is smaller but significantly negative at 16 employees as well. Overall, firms employing 15 employees are significantly more likely to move downward than upward, in a way consistent with asymmetric behaviour around the threshold.

[Figure 10 APPROXIMATELY HERE]

[Figure 11 APPROXIMATELY HERE]

[Table 5 APPROXIMATELY HERE]

\section{The 1990 Reform on Individual Dismissal}

In 1990 the Italian legislation on dismissal rules applied to small firms changed drastically. Before 1990, workers dismissed from small firms could not appeal the employer initiated dismissal, i.e. before 1990 firms employing less than 15 employees were not obliged to obey to "just-cause" rule for their individual dismissals. Since 1990, small firms are required to justify their dismissal in accordance to the labour code, and whenever the dismissal is ruled unfair, they are obliged to compensate the worker with a severance payment. The legislated severance payment varies between 2.5 and 6 monthly wages, with the actual payment linked to the seniority of the dismissed worker. As far as individual dismissals are concerned, after 1990 the difference in the EPL between small and large firms was reduced to the article 18 of the labour code: while large firms are obliged to rehire unlawfully dismissed workers, small firms can compensate workers through a severance payment. This policy change is akin to a tightening in EPL on small firms relative to large firms.

Unfortunately, it is not possible to treat the 1990 reform as a natural experiment, since in 1991 a collective dismissal procedure was introduced for firms employing more than 15 employees. As of 1991, whenever a large firm faces a credible risk of bankruptcy, and needs to dismiss at least 5 employees, it has the option to undergo (long) negotiations with the unions, and in case the dismissal is 
authorized no further liabilities are imposed on the firm. The collective dismissal procedure reduces EPL on the part of large firms, and may also reduce the cost of crossing the threshold for small firms.

In what follows we consider the behaviour of "large" firms with 20-25 employees and the behaviour of small firms with 6-10 workers. While we could obviously expand the range of small firms considered, we prefer to focus on the very small firms, since firms close to threshold are likely to be affected by the introduction of the collective dismissal procedure. We could also opt for "large" firms with 16-20 employees; however, to avoid spillover effects that might be present right above the threshold we prefer to be conservative.

Our focus is on the persistence behaviour. A stricter EPL on the part of small firms relative to large firms should translate in an increase in relative persistence and employment inaction. Table 6 reports summary statistics on the probability of inaction before and after the 1990 reform for the "small" and the "large" groups of firms. We distinguish between the service and the manufacturing sector. Employment persistence increases after 1990 among small firms for both sectors. For the service sector, the persistence probability increases by more than two percentage points, from 32.6 to 35.2. A quantitatively smaller rise is observed in the manufacturing sector. Table 6 shows also that firm level persistence of large firms declines in the service sector while slightly increases in the manufacturing sector. Overall, the difference of the differences is 2.9 in the service sector and 1.66 in the manufacturing sector. The question is whether such difference is statistical significant.

In Table 7 we look for a significant discontinuity in the persistence of small firms relative to large firms. The dependent variable in our regressions is $p p_{i t k}$ or the probability of inaction for firms of size $i$ between time $t$ and $t+l$ in sector $k$. With this definition of the dependent variable, the panel data we consider reaches 288 observations. The baseline regression model is the following

$$
\text { ppitk }=\gamma_{t}+\alpha^{*} \text { small }+\beta^{*} \text { small } 91+\delta^{*} \sec \text { tork }+ \text { uikt }
$$

where $\gamma_{t}$ is a time dummy, small is a dummy variable that takes the value of 1 if firm size is between 6 and 10, small91 is a dummy variable identical to small but with positive values only if the year $t$ is larger than 1990, sector is dummy variable that takes value of 1 if the probability refers to the service sector. The coefficient of interest is $\beta$, whose estimates are reported in Table 7 (model I), which refers to both the manufacturing and the service sector. The Table suggests that after 1990 the relative persistence of small firms increased significantly by 2.76 percentage points. As predicted, the 1990 reform increased relative inaction on the part of small firms. Column II presents the same model interacting small91 and sector; it finds that the overall effect is still around 2.7 percentage points, even though the effect of the service sector is slightly larger. Finally, the models labelled column III and column IV restrict the analysis to only one sector, reducing the size of the dataset from 288 to 144 observations. The Table suggests that the effect in the service sector is larger than the aggregate one, reaching 3.45 percentage points. Conversely the coefficient in the manufacturing sector is smaller and not significant. Overall, the results in Table 7 suggest that after 1990 the persistence of small firms relatively to large firms increased significantly by more than 2 percentage points. 


\section{Conclusions}

This paper fits into the empirical EPL literature, and provides fresh evidence on the links between employment dynamics and asymmetric EPL across the firm size distribution. We focused on the Italian institutional setting, where firms with more than 15 employees are obliged to rehire the dismissed employee when a judge rules the dismissal unfair. Small firms, by contrast, are only obliged to compensate the dismissed worker with a monetary transfer.

The paper found a significant, albeit quantitatively small, threshold effect. Specifically, it found that firms employing 14 and 15 employees have a probability of inaction that is 1.5 percent higher than what different non linear statistical models would predict. Similarly, the difference between the probability of moving down and moving up by one position falls slightly with firm size, but it features a 1.6 percent spike around the 15 employees threshold. Both these results are consistent with the predictions of our toy model of EPL with threshold effects. Finally, the paper tests the effect of the 1990 EPL reform which increased firing costs for small firms relatively to large firms. It finds that relative inaction on the part of small firms increased significantly.

Our general conclusion - significant but small threshold effects- is also consistent with an existing study based on a different country and a different piece of legislation. Specifically, Wagner et al. (2001) studied the threshold effects of the disability law in Germany, a piece of legislation that forces firms larger than 15 employees to hire disable workers. Using a technique similar to the one presented in this paper, Wagner et al. find that the German disability law induces quantitatively small effects on firm level employment dynamics. Future research should try similar tests on other legislation and should try to rationalize why such threshold rules exist in the first place, along the lines of the work of Boeri - Jimeno (2003) who offer an interesting interpretation based on different monitoring technologies between small and large firms.

\section{References}

ACEMOGLU D. - ANGRIST J. (2001), "The Consequence of EPL: The Case of the Employment Disability Act”, Journal of Political Economy, vol. 109(5), pp. 915-57.

ANASTASIA B. (1999), "I vantaggi Competitivi della piccola impresa nell'utilizzo del fattore lavoro: formazione, costi, obblighi e norme" in "La Questione Dimensionale Nell'Industria Italiana" ed. by F. Traù, Bologna, Il Mulino.

BAFFI G. - BAFFI E. (1999), "Il diritto del mercato del lavoro e le soglie dimensionali: presentazione di un quadro sinottico" in "La Questione Dimensionale Nell'Industria Italiana” ed. by F. Traù, Bologna, Il Mulino

BARTELSMAN E. - SCARPETTA S. - SCHIVARDI F. (2001), Comparative Analysis of Firm Demographics and Survival: Micro Level Evidence for the OECD Countries, Mimeo, Bank of Italy.

BLANCHARD O. - PORTUGAL P. (2001), "What Lies Behind the Unemployment Rate: Comparison of U.S. and Portugal”, American Economic Review, vol. 91, pp. 993-1008 
BENTOLILA S. - BERTOLA G. (1990), "How Bad is Eurosclerosis", Review of Economic Studies, vol. 57, pp. 381-402.

BERTOLA G. (1999), "Microeconomic Perspectives on Aggregate Labor Markets", in Handobook of Labor Economics, ed. by O. Ashenfelter - D. Card , pp 2985-3028, North Holland

BOERI T. - JIMENO J. (2003), "The Effects of Employment Protection: Learning From Variable Enforcement", mimeo Bocconi University.

CONTINI B. (2002), Labour Mobility and Wage Dynamics in Italy (ed. by), Rosenberg \& Sellier Publishing.

GARIBALDI P. - VIOLANTE G. (2002), "Severance Payments and Firing Taxes in Search Economies: A Comparison”. CEPR Discussion Paper 3636.

KUGLER A. (1999), "The Impact of Firing Costs on Turnover and Unemployment: Evidence from the Colombian Labor Market Reform," International Tax and Public Finance, vol. 6(3), pp. 389410 .

LAZEAR, E. (1990), "Job Security Provisions and Employment", Quarterly Journal of Economics, vol. 105, pp. 699-726.

ISTAT (2002), Annual Report, Available on line at www.istat.it

OECD (1999), Employment Outlook. Paris

SCHIVARDI F. (2000), Rigidità nel Mercato del Lavoro, Disoccupazione e Crescita, Giornale degli Economisti, vol 59(1), pp.115-141.

SUTTON J. (1997), “Gibrat's Legacy” Journal of Economic Literature, vol 35, pp. 40-59.

TATTARA G. (1999), "Perché le piccole imprese non diventano grandi? I lacci posti dalle "regole del lavoro"”, Economia e Società Regionale, vol. 3.

TRAÙ F. (1999), Il Riemergere della small scale production nei paesi industriali: rassegna della letterature empirica e primi confronti internazionali delle tendenze di lungo periodo" in " $\mathrm{La}$ Questione Dimensionale Nell'Industria Italiana" ed. by F. Traù, Bologna, Il Mulino.

WAGNER J. - SCHNABEL C. - KÖLLING A. (2001), "Threshold Values in German Labour Law and Job Dynamics in Small Firms: The Case of the Disability Law", Ifo Studien-Zeitschrift für empiriche Wirtschaftsforschung, pp. 65-75. 
Table 1. Number of Firms by Size in the sample and sampling ratio with respect to INPS Observatory

\begin{tabular}{lrrrrrrrrr}
\hline & 1987 & 1988 & 1989 & 1990 & 1991 & 1992 & 1993 & 1994 & 1995 \\
\hline Ratio Sample-Observatory & 5.4 & 5.5 & 5.4 & 5.2 & 5.6 & 5.6 & 6.1 & 5.9 & 6.0 \\
& & & & & & & & & \\
By Firm Size: & & & & & & & & & \\
Up to 5 employees & & & & & & & & & \\
$\quad$ Ratio Sample -Observatory & 1.9 & 1.9 & 1.9 & 1.9 & 1.3 & 1.7 & 2.3 & 2.2 & 2.2 \\
$\quad$ Number of Firms & 12720 & 12978 & 12655 & 8793 & 11982 & 14561 & 14424 & 14280 & 12091 \\
From 6 to 9 employees & & & & & & & & & \\
$\quad$ Ratio Sample -Observatory & 6.5 & 6.5 & 6.5 & 6.4 & 4.6 & 5.8 & 7.4 & 7.2 & 7.2 \\
$\quad$ Number of Firms & 6578 & 6613 & 6565 & 4659 & 5932 & 7392 & 7268 & 7206 & 6105 \\
10 to 19 employees & & & & & & & & & \\
$\quad$ Ratio Sample -Observatory & 11.8 & 11.9 & 11.6 & 11.3 & 8.8 & 10.7 & 13.3 & 12.9 & 12.9 \\
$\quad$ Number of Firms & 9743 & 10090 & 9927 & 7361 & 9004 & 10914 & 10405 & 10745 & 8995 \\
\hline
\end{tabular}


Table 2. Average Transition Probability by Firm Size All Economy, Average 1987-1995

\begin{tabular}{|c|c|c|c|c|c|}
\hline \multirow[b]{2}{*}{ Size } & \multirow{2}{*}{$\mathrm{p}(\mathrm{x}, \mathrm{x}-2)$} & \multirow{2}{*}{$\begin{array}{r}\mathrm{p}(\mathrm{x}, \mathrm{x}-1) \\
12\end{array}$} & \multicolumn{3}{|c|}{$\mathrm{p}(\mathrm{x}, \mathrm{x}) \mathrm{p}(\mathrm{x}, \mathrm{x}+1) \mathrm{p}(\mathrm{x}, \mathrm{x}+2)$} \\
\hline & & & 13 & 14 & 15 \\
\hline 1 & & & 72.2 & 17.3 & 5.1 \\
\hline 2 & & 14.8 & 57.3 & 17.5 & 5.3 \\
\hline 3 & 4.4 & 17.3 & 48.4 & 17.3 & 6.1 \\
\hline 4 & 5.5 & 18.1 & 42.7 & 17.7 & 6.9 \\
\hline 5 & 6.2 & 18.3 & 37.8 & 17.9 & 7.8 \\
\hline 6 & 6.6 & 17.9 & 34.6 & 17.9 & 8.0 \\
\hline 7 & 7.5 & 17.0 & 31.2 & 18.0 & 8.6 \\
\hline 8 & 7.8 & 16.9 & 29.0 & 17.4 & 9.2 \\
\hline 9 & 8.3 & 17.0 & 27.9 & 16.5 & 9.3 \\
\hline 10 & 8.2 & 16.7 & 26.5 & 16.6 & 8.8 \\
\hline 11 & 8.0 & 16.5 & 24.3 & 16.8 & 9.7 \\
\hline 12 & 8.5 & 16.3 & 23.2 & 16.3 & 9.7 \\
\hline 13 & 8.7 & 15.9 & 22.8 & 15.7 & 10.3 \\
\hline 14 & 9.3 & 15.3 & 22.1 & 16.9 & 9.0 \\
\hline 15 & 9.3 & 15.7 & 21.9 & 14.1 & 9.0 \\
\hline 16 & 9.3 & 15.3 & 19.1 & 14.4 & 9.6 \\
\hline 17 & 9.3 & 14.8 & 18.4 & 14.5 & 9.4 \\
\hline 18 & 9.5 & 14.0 & 18.2 & 13.8 & 9.2 \\
\hline 19 & 9.1 & 14.0 & 17.8 & 12.9 & 9.3 \\
\hline 20 & 8.3 & 13.1 & 18.7 & 12.8 & 9.4 \\
\hline 21 & 9.6 & 13.6 & 17.0 & 12.2 & 8.8 \\
\hline 22 & 9.4 & 12.6 & 16.0 & 13.1 & 8.8 \\
\hline 23 & 8.3 & 12.8 & 16.0 & 12.0 & 8.6 \\
\hline 24 & 8.2 & 13.6 & 15.0 & 11.6 & 9.0 \\
\hline 25 & 8.4 & 12.2 & 15.0 & 12.0 & 8.7 \\
\hline 26 & 9.0 & 11.6 & 14.3 & 11.5 & 8.2 \\
\hline 27 & 9.6 & 11.6 & 13.7 & 11.3 & 8.9 \\
\hline 28 & 9.2 & 11.7 & 13.0 & 12.1 & 34.2 \\
\hline 29 & 7.9 & 12.7 & 12.8 & 45.7 & \\
\hline 30 or more & 0.7 & 0.9 & 95.4 & & \\
\hline
\end{tabular}

11 Probability of Reducing Size by 2 Employees 12 Probability of Reducing Size by 1 Employee 13 Probability of Inaction 14 Probability of Increasing Size by 1 Employee 15 Probability of Increasing Size by 2 Employees 
Table 3. Persistence Probability, all economy, 1987-1995

\begin{tabular}{|c|c|c|c|c|c|}
\hline \multicolumn{2}{|l|}{$\begin{array}{l}\text { RHS Variables } \\
\text { Dummies: window size } \\
\text { Size Dummy }\end{array}$} & $\begin{array}{c}\text { Model: } 1 \\
\text { Inverse of Size } \\
1 \\
\text { Coefficient } \\
\end{array}$ & $\begin{array}{c}\text { Model: } 2 \\
\text { Inverse of Size } \\
3 \\
\text { Coefficient } \\
\end{array}$ & $\begin{array}{c}\text { Model: } 3 \\
\text { Inverse of Size; Size } \\
1 \\
\text { Coefficient } \\
\end{array}$ & $\begin{array}{c}\text { Model: } 4 \\
\text { Inverse of Size; Size } \\
3 \\
\text { Coefficient } \\
\end{array}$ \\
\hline & 6 & $-2.28 * *$ & & 0.4 & \\
\hline & 7 & -1.29 & & $-0.44 * * *$ & \\
\hline & 8 & -0.42 & & $-0.38^{* *}$ & \\
\hline & 9 & $0.93 * *$ & 0.77 & $0.49^{* * *}$ & 0.29 \\
\hline & 10 & $1.24 * * *$ & -0.29 & $0.53 * *$ & 0.08 \\
\hline & 11 & $0.52 *$ & $0.88^{* *}$ & $-0.38^{*}$ & -0.11 \\
\hline & 12 & $0.58 * *$ & $0.86^{* *}$ & $-0.4^{*}$ & -0.23 \\
\hline & 13 & $1.22^{* * *}$ & $1.18^{* * *}$ & 0.25 & 0.14 \\
\hline & 14 & $1.40^{* * *}$ & $1.71 * * *$ & $0.47^{*}$ & $0.83 * *$ \\
\hline & 15 & $2.02 * * *$ & $1.14^{*}$ & $1.19 * * *$ & 0.21 \\
\hline & 16 & -0.31 & 0.44 & $-1.14 * * *$ & -0.47 \\
\hline & 17 & $-0.51^{* *}$ & -0.28 & $-1.19 * * *$ & $-1.09 * * *$ \\
\hline & 18 & 0.07 & -0.11 & $-0.41 * *$ & $-0.69 * *$ \\
\hline & 19 & 0.13 & 0.62 & -0.17 & 0.28 \\
\hline & 20 & $1.42 * * *$ & -0.06 & $1.31^{* * *}$ & $0.32 *$ \\
\hline & 21 & 0.19 & & $0.29 *$ & \\
\hline & 22 & $-0.57^{*}$ & & $-0.24^{*}$ & \\
\hline & 23 & -0.33 & & $0.24 *$ & \\
\hline & 24 & $-1.09 * * *$ & & $-0.28 * *$ & \\
\hline Constant $\backslash 1$ & & $10.3^{* * *}$ & $10.3^{* * *}$ & $16.6^{* * *}$ & $16.6^{* * *}$ \\
\hline Inverse of Size & & $160.36^{* * *}$ & $160.36^{* * *}$ & $106.05^{* * *}$ & $106.05^{* * *}$ \\
\hline Size & & & - & $-0.32 * * *$ & $-0.32 * * *$ \\
\hline Time Dummies & & Yes & Yes & Yes & Yes \\
\hline Num. Observations & & 198 & 198 & 198 & 198 \\
\hline $\mathrm{R}^{\wedge} 2$ without dummy & & 0.92 & 0.92 & 0.94 & 0.94 \\
\hline
\end{tabular}

$*, * *$, and $* * *$ refer to 90,95 and 99 percent significance

$\backslash 1$ below line: estimated coefficients when size dummies are excluded

Table 4. Bootstrapped Standard Deviation for Persistence Probability, year 1994-1995

\begin{tabular}{|c|c|c|c|c|c|c|}
\hline \multirow[t]{4}{*}{ Size } & \multirow[t]{4}{*}{ Value } & \multirow[t]{4}{*}{ Std Dev. } & \multicolumn{2}{|c|}{ 95\% Confidence Interval } & \multicolumn{2}{|c|}{$95 \%$ Confidence Interval } \\
\hline & & & \multirow{2}{*}{\multicolumn{2}{|c|}{ assuming normality }} & \multirow{2}{*}{\multicolumn{2}{|c|}{$\begin{array}{c}\text { bootstrapped } \\
\text { bias corrected percentiles }\end{array}$}} \\
\hline & & & & & & \\
\hline & & & Lower & Higher & Lower & Higher \\
\hline 12 & 23.91 & 1.21 & 21.53 & 26.29 & 21.66 & 26.48 \\
\hline 13 & 22.39 & 1.04 & 20.13 & 24.65 & 20.43 & 24.85 \\
\hline 14 & 21.9 & 1.12 & 19.54 & 24.26 & 19.66 & 24.26 \\
\hline 15 & 23.44 & 1.29 & 20.92 & 25.96 & 20.99 & 25.81 \\
\hline 16 & 18.41 & 1.28 & 15.89 & 20.93 & 16.02 & 21.24 \\
\hline 17 & 21.79 & 1.39 & 19.06 & 24.53 & 19.32 & 24.6 \\
\hline 18 & 17.83 & 1.36 & 15.16 & 20.49 & 15.31 & 20.44 \\
\hline
\end{tabular}


Table 5. Net Probability of Increasing One Position, 1987-1995

\begin{tabular}{|c|c|c|c|}
\hline Sector & All Economy & Manufacturing & Service \\
\hline RHS Variables & Size & Size & Size \\
\hline Dummies: window size & 1 & 1 & 1 \\
\hline Size Dummy & Coefficient & Coefficient & Coefficient \\
\hline 6 & -0.2 & 0.26 & 0.33 \\
\hline 7 & $0.86 * * *$ & 0.24 & $1.48 * * *$ \\
\hline 8 & $0.52 *$ & $0.52 *$ & 0.18 \\
\hline 9 & $-0.74 * * *$ & -0.1 & $-1.29 * * *$ \\
\hline 10 & -0.22 & 0.05 & $0.22 *$ \\
\hline 11 & 0.26 & $0.6^{* *}$ & $-1.14 * * *$ \\
\hline 12 & 0.07 & -0.03 & $0.93 * * *$ \\
\hline 13 & -0.04 & -0.05 & 0 \\
\hline 14 & $1.83 * * *$ & $2.18 * * *$ & $0.71 * * *$ \\
\hline 15 & $-1.58 * * *$ & $-2.10 * * *$ & $-1.58 * * *$ \\
\hline 16 & $-0.69 * * *$ & $-0.77 * * *$ & $-1.77 * * *$ \\
\hline 17 & 0.02 & $-0.41 *$ & $0.63 * *$ \\
\hline 18 & 0.129 & $-0.86 * * *$ & $1.59 * * *$ \\
\hline 19 & $-0.615 * * *$ & -0.12 & $-1.23 * * *$ \\
\hline 20 & 0.04 & 0.1 & 0.07 \\
\hline 21 & $-0.85 * * *$ & $-1.92 * * *$ & $-1.5 * * *$ \\
\hline 22 & $1.22 * * *$ & $0.6^{*}$ & $2.92 * * *$ \\
\hline 23 & -0.18 & 0.01 & -0.02 \\
\hline 24 & $-1.71 * * *$ & $-1.59 * * *$ & $-1 *$ \\
\hline $\bar{C}$ Constant $\backslash 1$ & $10.35 * * *$ & $12.20 * * *$ & $8.36 * * *$ \\
\hline Size & $160.36^{* * *}$ & $145.51 * * *$ & $201.167 * * *$ \\
\hline Time Dummies & Yes & Yes & Yes \\
\hline Num. Observations & 198 & 198 & 198 \\
\hline $\mathrm{R}^{\wedge} 2$ without dummy & 0.92 & 0.87 & 0.85 \\
\hline
\end{tabular}

$* * *$ and $* * *$ refer to 90,95 and 99 percent significance

$\backslash 1$ below line: estimated coefficients when size dummies are excluded 
Table 6. Persistence Before and After 1990

\begin{tabular}{lrrrr}
\hline & \multicolumn{2}{c}{ Services } & \multicolumn{3}{c}{ Manufacturing } \\
\cline { 2 - 5 } & Small & Large & Small & Large \\
\hline before 1990 & 32.54 & 16.59 & 28.52 & 16.86 \\
Difference before 1990 & 15.95 & & 11.66 & \\
after 1991 & 35.23 & 16.36 & 31.24 & 17.92 \\
Difference After 1990 & 18.87 & & 13.32 & \\
Difference in Difference: & 2.92 & & 1.66 & \\
\hline
\end{tabular}

Small refers to size 6-10

Large refers to size 20-25

Table 7. Persistence Before and After 1990. Regression

Dependent Variable: Persistence Probability

in small firms (6-10 employees) and large firms (20-25 employees) in sector i

\begin{tabular}{|c|c|c|c|c|}
\hline Model & (I) & (II) & (III) & (IV) \\
\hline Sector & All Economy & All Economy & Service & Manufacturing \\
\hline small firms $\backslash 1$ & $16.1 * * *$ & - & - & - \\
\hline small firms after $1991 \backslash 2$ & $2.76^{* *}$ & - & - & - \\
\hline small firm service & - & $18.77^{* *}$ & $18.36^{* *}$ & \\
\hline small firm service after 1991 & - & $2.72 *$ & $3.45^{* *}$ & \\
\hline small firm manufact & - & $13.34 * *$ & - & $13.75^{* * *}$ \\
\hline small firm manufact. after 1991 & - & $2.80^{*}$ & - & 2.07 \\
\hline time dummies & Yes & Yes & Yes & Yes \\
\hline sector dummies & Yes & Yes & No & No \\
\hline $\mathrm{R}^{\wedge} 2$ & 0.75 & 0.77 & 0.79 & 0.74 \\
\hline Observations & 288 & 288 & 144 & 144 \\
\hline
\end{tabular}

1 Dummy Variable for small firms employing 6-10 employees

12 Dummy Variable for small firms (6-10) after 1990 


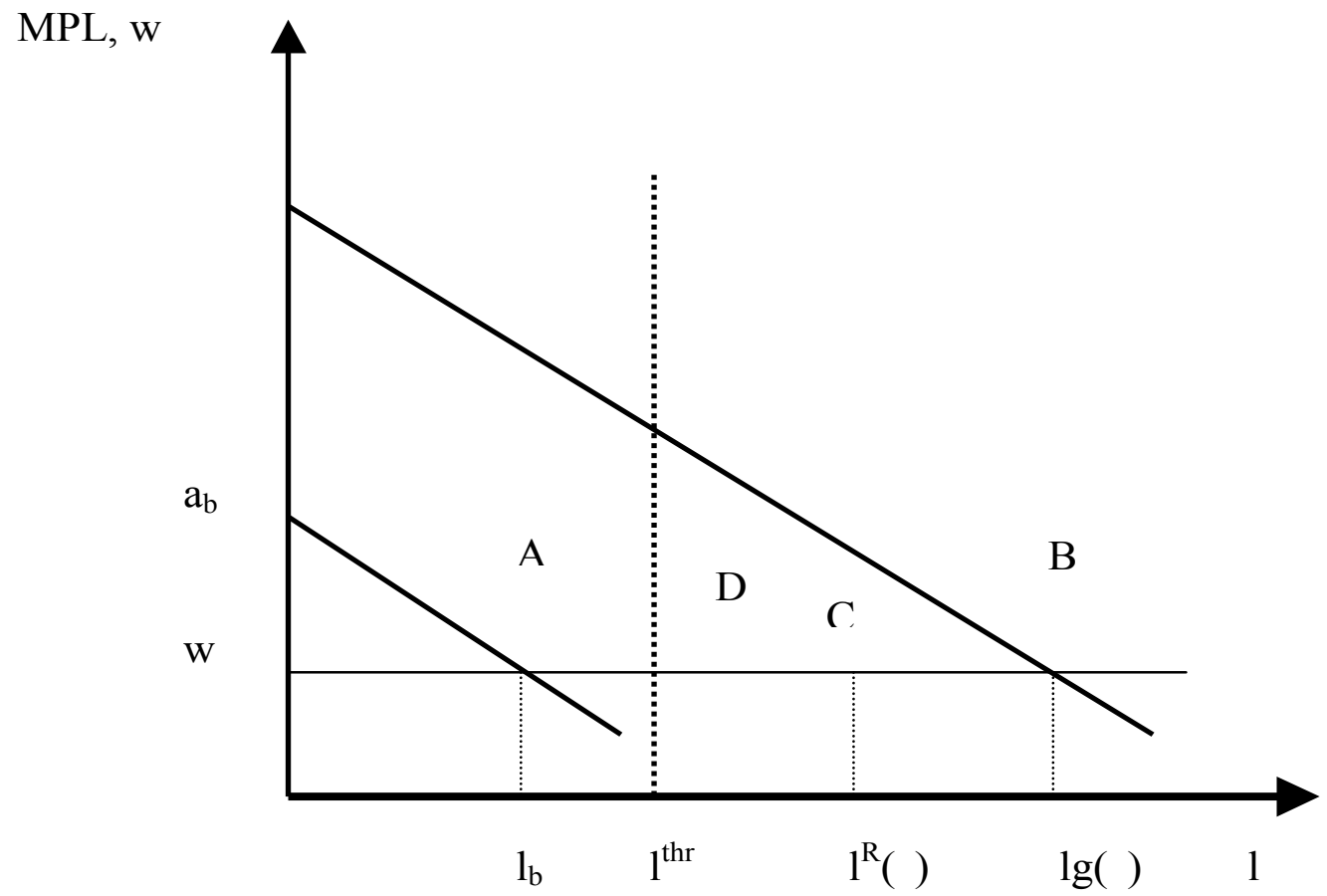

Figure 1. Employment Level in Efficient, Rigid and Stay Small Regime of a type$\square$ firm

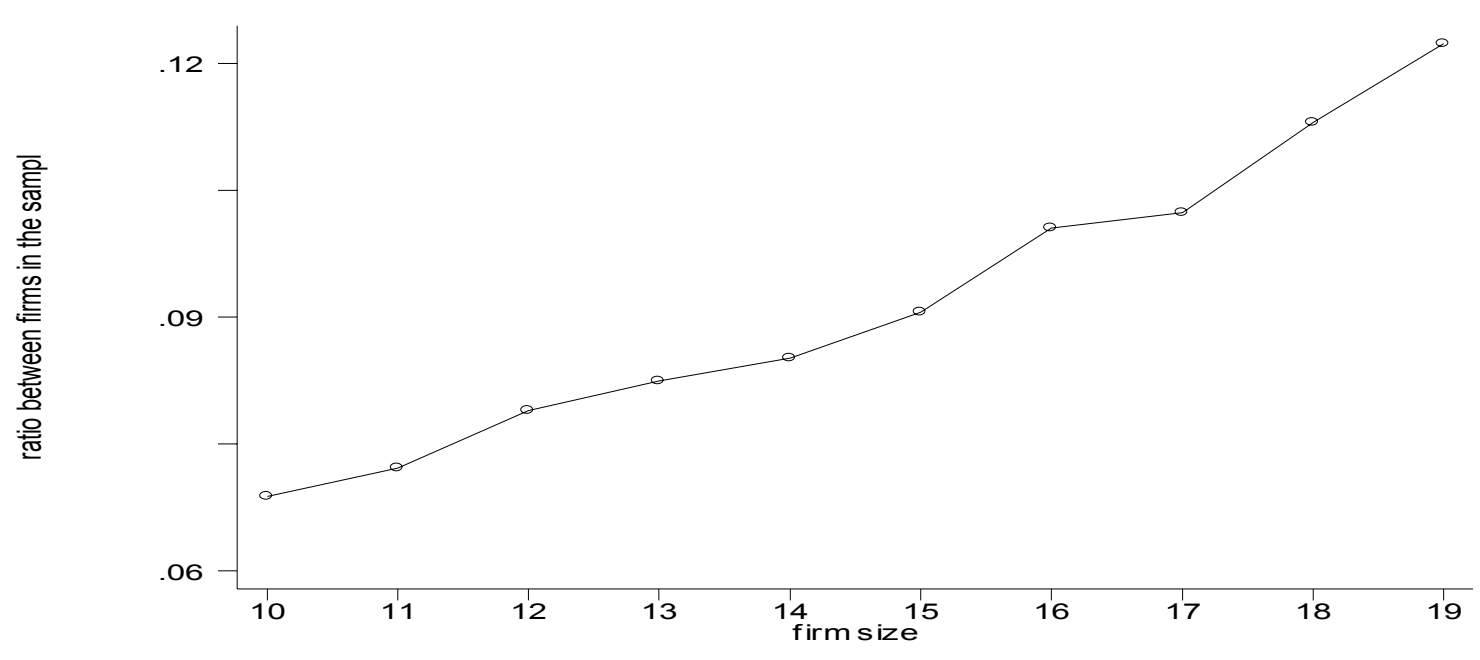

Figure 2. Relative Number of Firms by Size in our sample and in Istat Data 


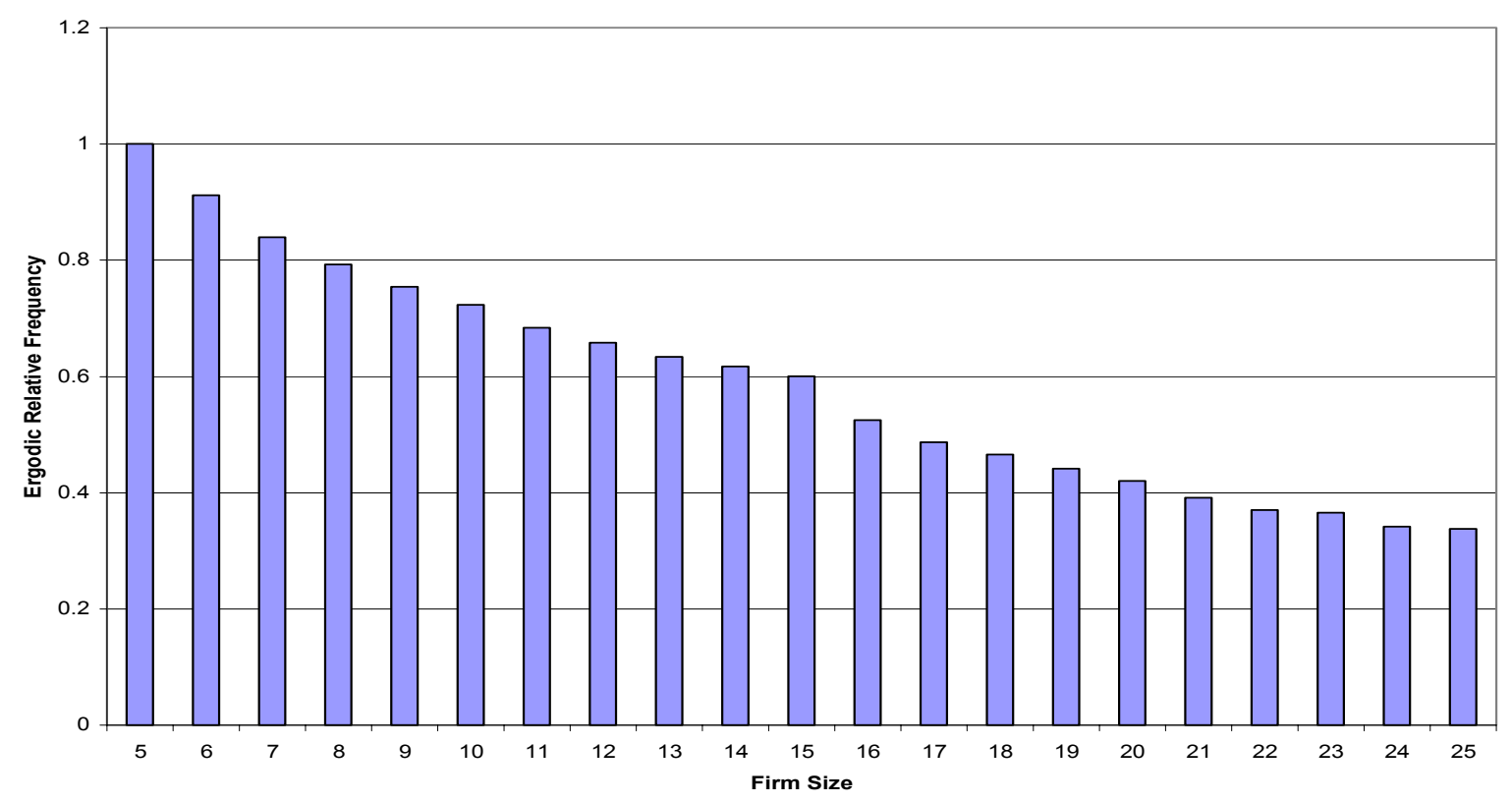

Figure 3. Implied Ergodic Firm Size Distribution (Relative to No. of Firms in Size 5)

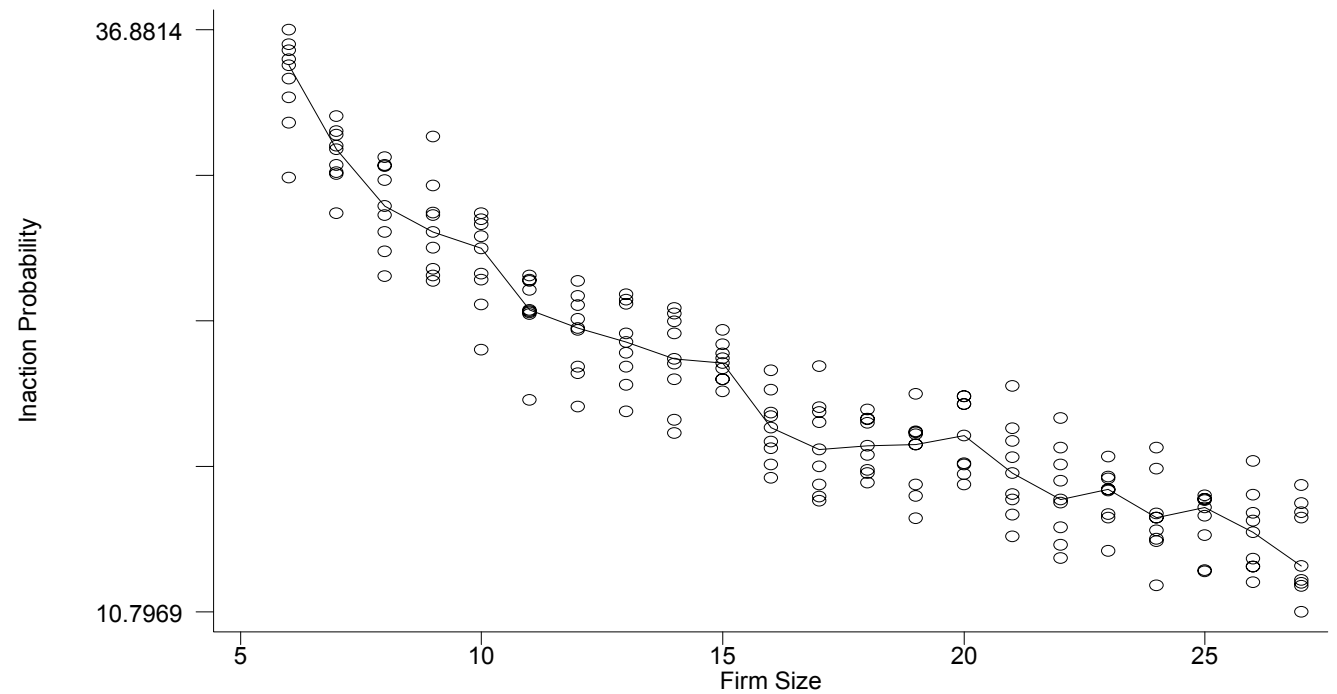

Figure 4. Inaction Probability by Firm Size in Different Years: 1987-1995

Line connecting median values 


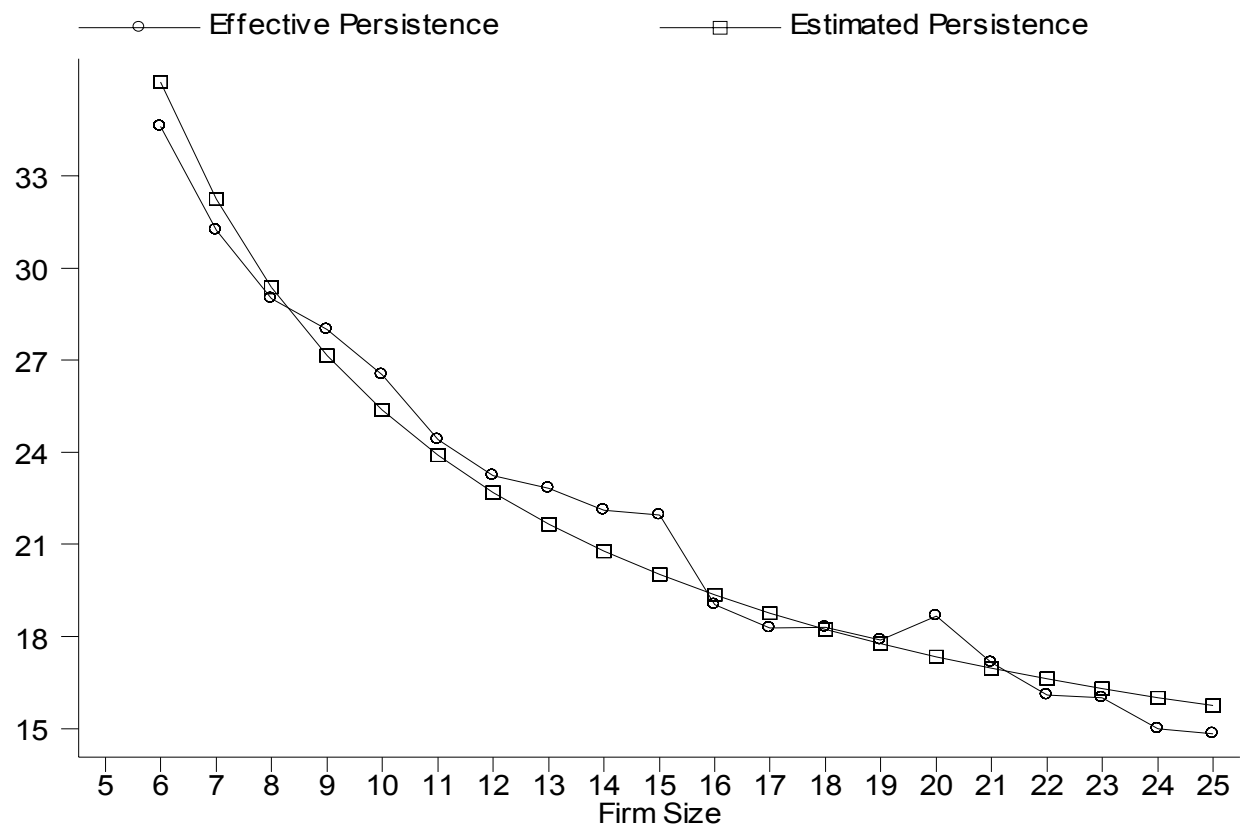

Figure 5. Effective and Estimated Inaction Probability: 1987-1995

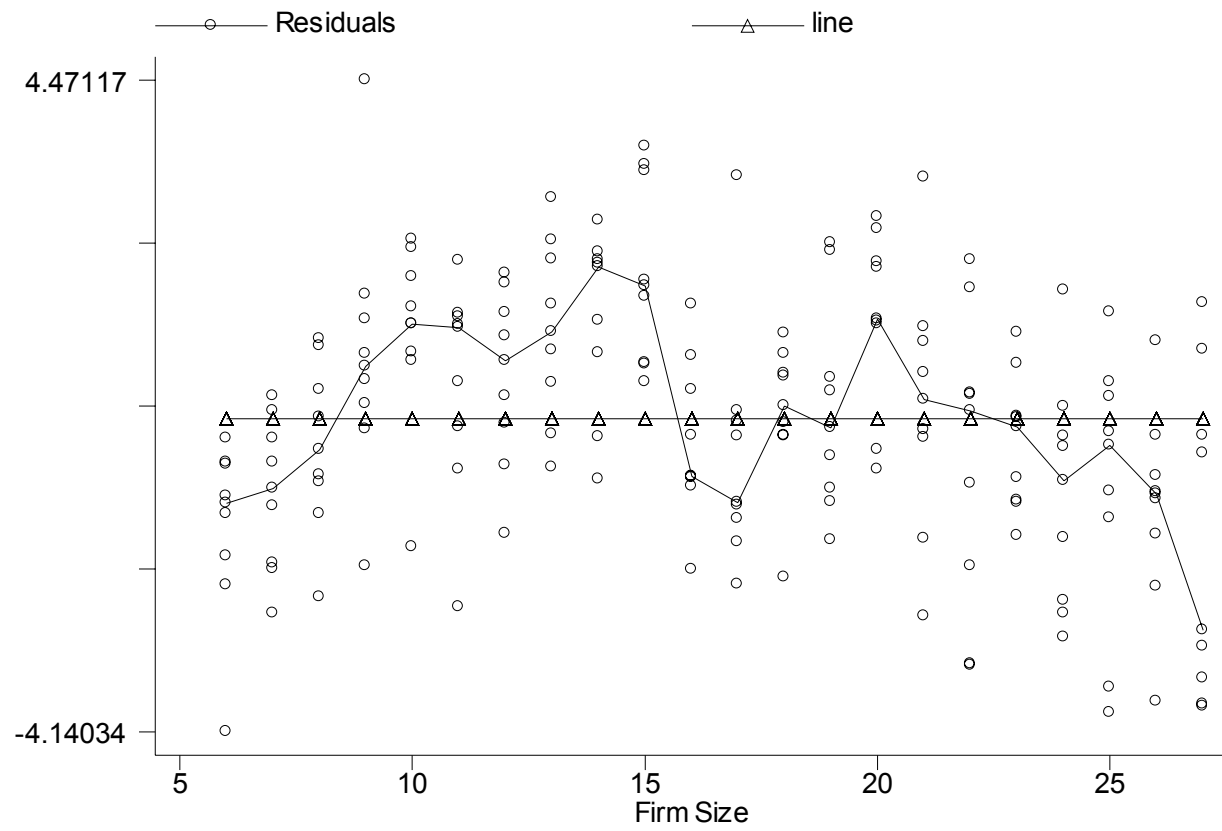

Figure 6. Residuals from Baseline Persistence Probability Model by Firm Size Line connecting median values Line at zero 


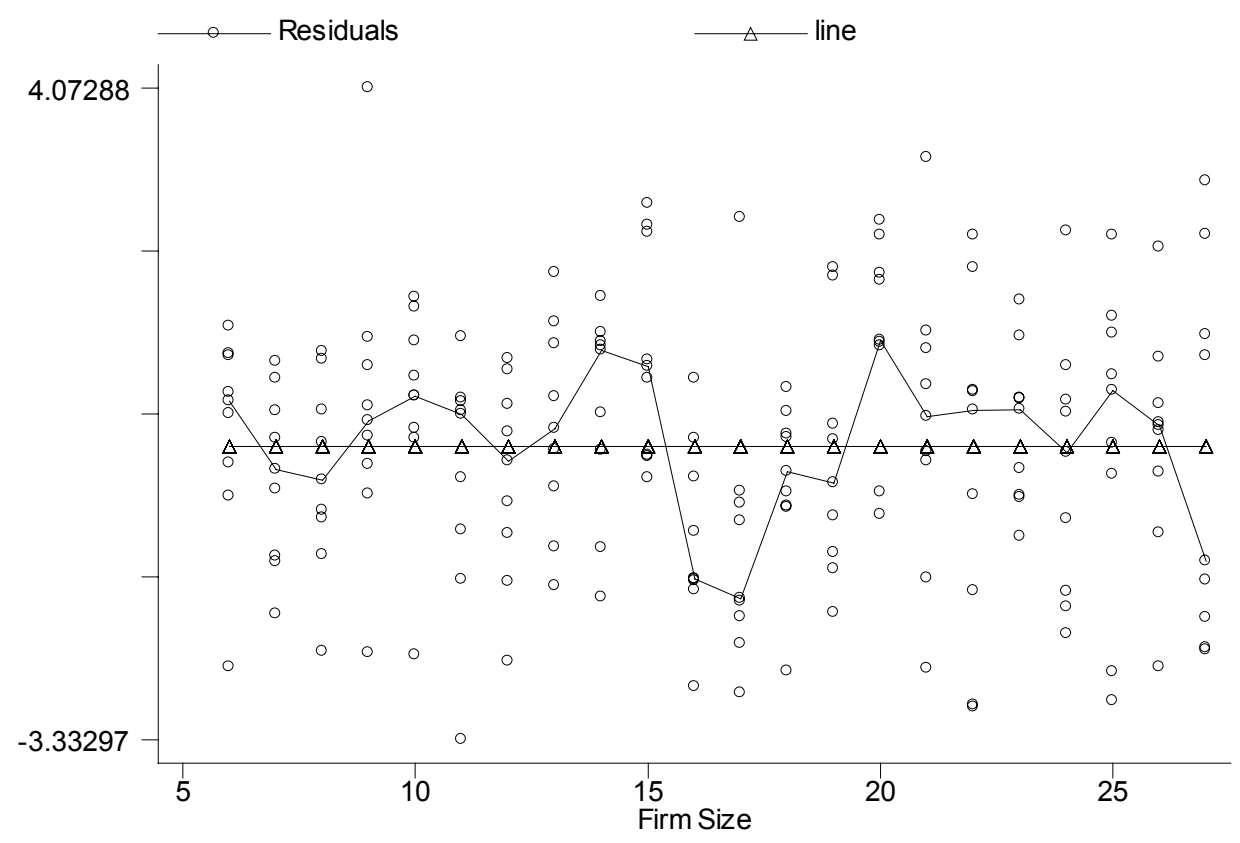

Figure 7. Residuals of Persistence Probability with Size and Inverse of Size Line connecting median values

Line at zero

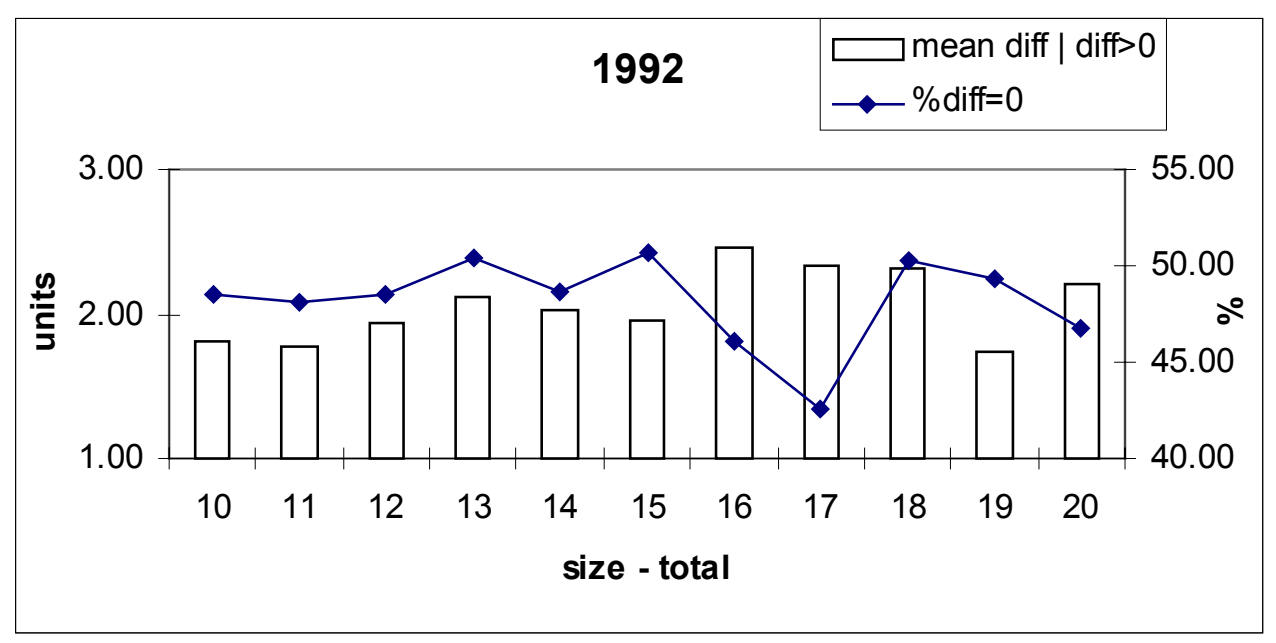

Figure 8. Labour code definition of employment, Turin, 1992

Left axis: Absolute difference total employment-labour code employment if difference is positive. Right axis: share of firms where total employment equals labour code definition of employment. Firm size is total employment 


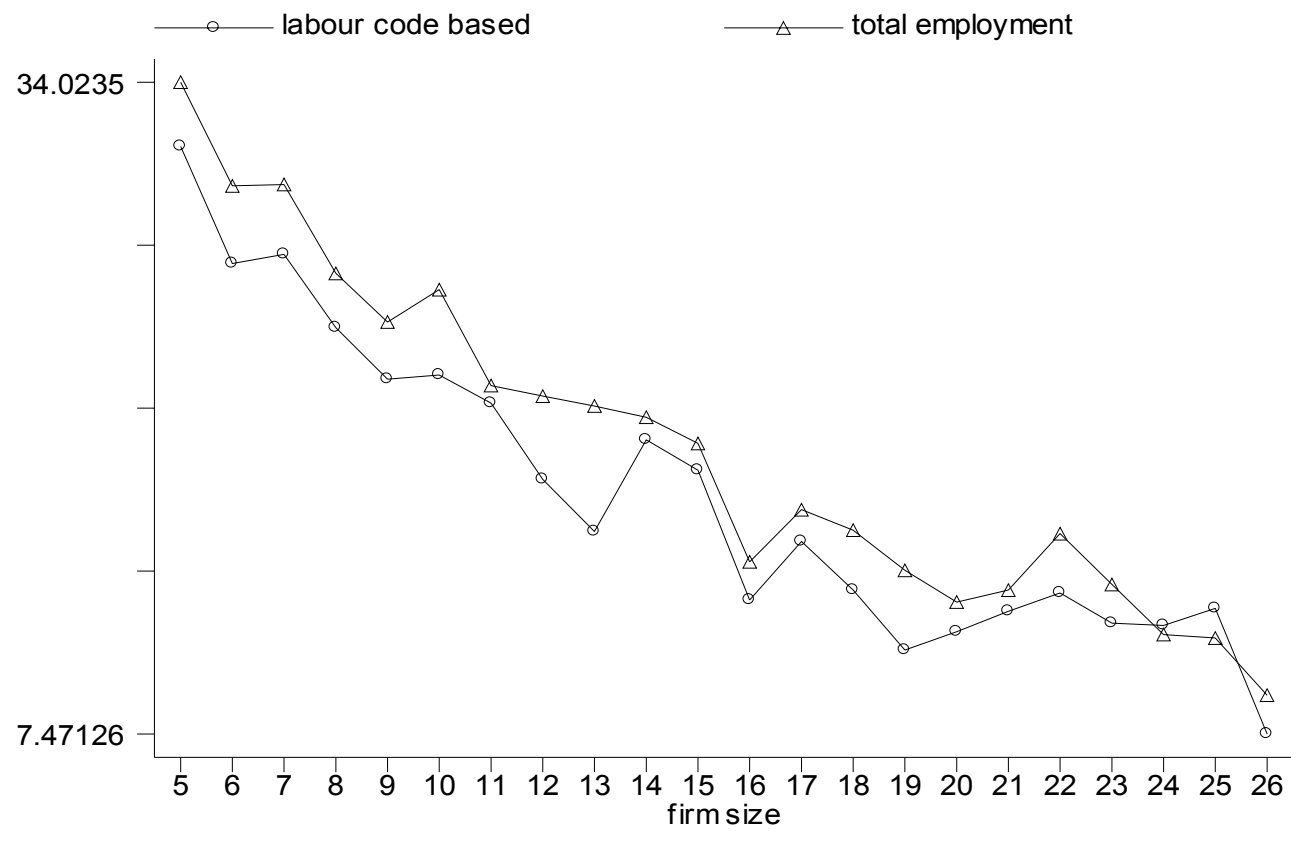

Figure 9. Persistence by firm Size in Total Employment and Labour Code Based Employment, Turin, 1990-1992

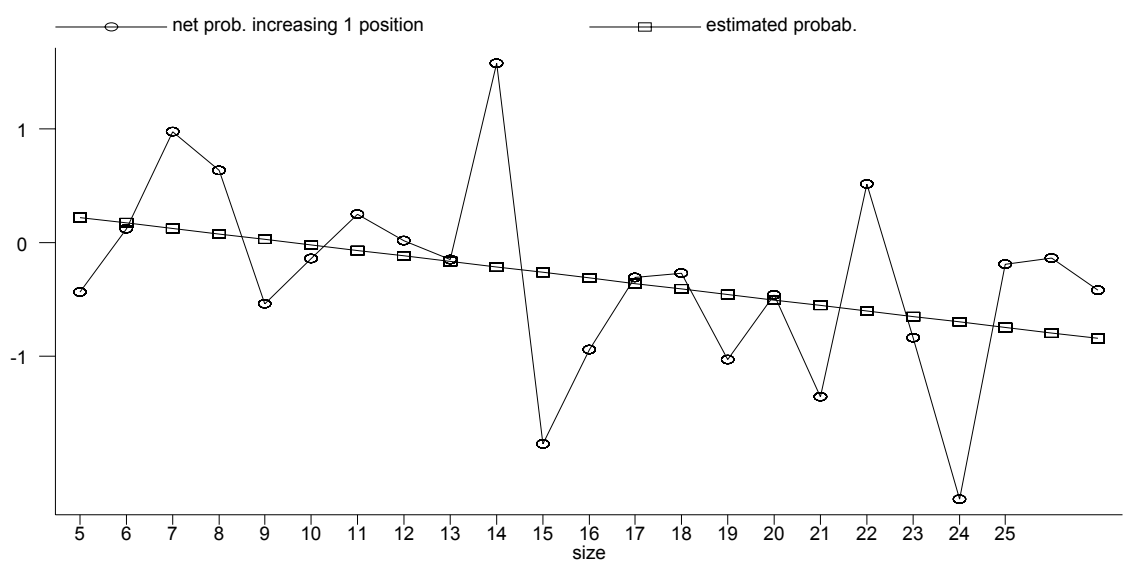

Figure 10. Net Probability of Increasing employment by One Position by Size: 1987-1995 


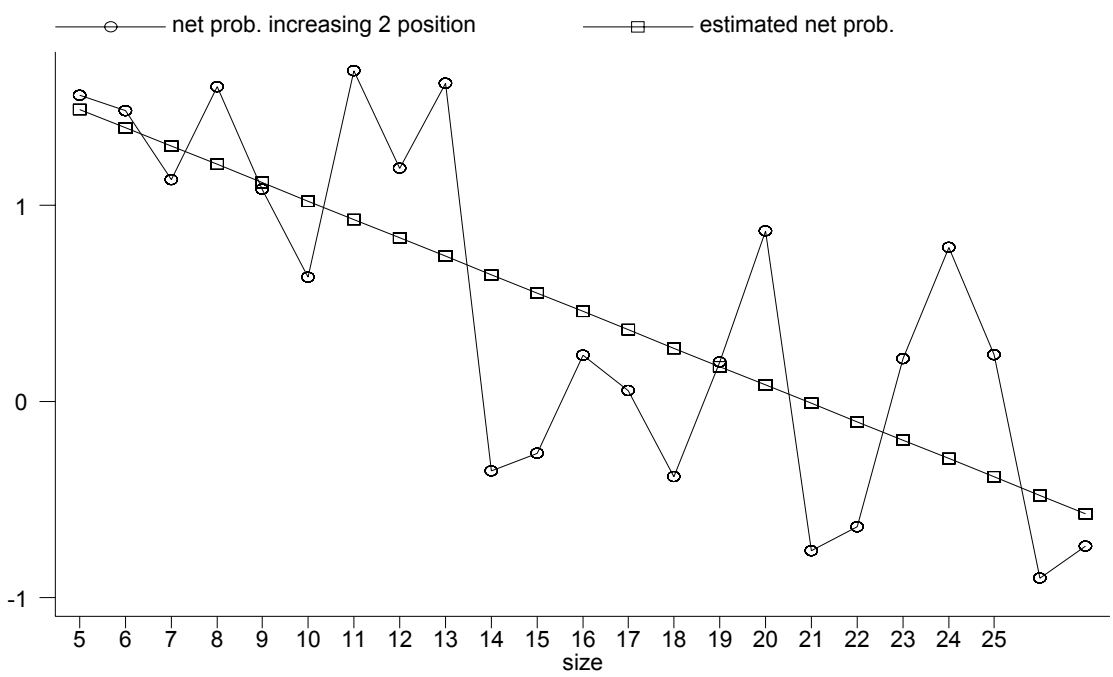

Figure 11. Net Probability of Increasing employment by Two Positions by Size: 19871995 